\title{
Assessing the effects of marine protected area (MPA) on a reef fish assemblage in a northwestern Mediterranean marine reserve: Identifying community-based indicators
}

\author{
J. Claudet ${ }^{a, b^{*}}$, D. Pelletier ${ }^{b}$, J.-Y. Jouvenel ${ }^{c}$, F. Bachet ${ }^{d}$ and R. Galzin ${ }^{a}$ \\ ${ }^{a}$ CNRS-EPHE/IFREMER, UMR 8046 CNRS, 52 Avenue Paul Alduy, 66860 Perpignan Cedex, France \\ ${ }^{b}$ Département EMH, IFREMER, BP 21105, 44311 Nantes Cedex 03, France \\ ${ }^{\mathrm{C}} \mathrm{P} 2 \mathrm{~A}$ Development, 17, rue Pierre et Marie Curie, 34110 Mireval, France \\ ${ }^{\mathrm{d}}$ Parc Marin de la Côte Bleue, Maison de la Mer, BP 37, 13960 Sausset-les-Pins, France \\ *: Corresponding author : Tel.: +33 4686621 90/20 55; fax: +33 4685036 86. joachim.claudet@gmail.com
}

\begin{abstract}
Marine protected areas (MPAs) are increasingly envisaged as a tool to manage coastal ecosystems and fisheries. Assessment of their performance with respect to management objectives is therefore important. A number of MPAs provided conservation benefits for fished species. Observed benefits do not apply to all species at all times, and responses to protection are also highly variable among fish taxa. Among the many empirical studies on marine reserves, only a few designs considered 'before and after data' and spatial variation. In this paper, we are interested in assessing the effect of a no-take reserve on the reef fish assemblage in a northwestern Mediterranean example. Data were obtained from a three-year survey using underwater visual censuses (UVC), before and after MPA establishment. Permutational multivariate analysis of variance (PERMANOVA) and multivariate regression trees (MRT) were used to evaluate the effects of reserve protection on the reef fish assemblage, while accounting for habitat. Modelled biological responses were abundances and diversity indices calculated at different levels of the assemblage. Significant effects were found for many of these metrics. In addition to PERMANOVA, univariate models provided more insight into the magnitude and direction of effects. The most sensitive metrics were related to large species and species targeted by fishing. These results may be used to choose the metrics that are more suitable as community-based indicators of MPA impact in the perspective of monitoring programs.
\end{abstract}

Keywords: Impact assessment; Marine protected area; Ecological indicator; Permutational multivariate analysis of variance; Multivariate regression trees; Reef fish assemblage; Northwestern Mediterranean 
Assessing the effects of Marine Protected Area (MPA) on a reef fish assemblage in a northwestern Mediterranean marine reserve: identifying community-based indicators

\author{
J. Claudet ${ }^{*, 1,2}$, D. Pelletier ${ }^{2}$, J.-Y. Jouvenel ${ }^{3}$, F. Bachet $^{4}$, R. Galzin ${ }^{1}$ \\ ${ }^{1}$ EPHE UMR 8046 CNRS, 52, avenue Paul Alduy, 66860 Perpignan Cedex, France \\ ${ }^{2}$ Département EMH, IFREMER, BP 21105, 44311 Nantes Cedex 03, France \\ ${ }^{3}$ P2A Development, 17, rue Pierre et Marie Curie, 34110, Mireval, France \\ ${ }^{4}$ Parc Marin de la Côte Bleue, Maison de la Mer, BP 37, 13960 Sausset-les-Pins, France
}

\begin{abstract}
Marine Protected Areas (MPAs) are increasingly envisaged as a tool to manage coastal ecosystems and fisheries. Assessment of their performance with respect to management objectives is therefore important. A number of MPAs provided conservation benefits for fished species. Observed benefits do not apply to all species at all times, and responses to protection are also highly variable among fish taxa. Among the many empirical studies on marine reserves, only a few designs considered before and after data and spatial variation. In this paper, we were interested in assessing the effect of a no-take reserve on the reef fish assemblage in a northwestern Mediterranean example. Data were obtained from a three-year survey using Underwater Visual Censuses (UVC), before and after MPA establishment. Permutational multivariate analysis of variance (PERMANOVA) and Multivariate Regression Trees (MRT) were used to evaluate the effects of reserve protection on the reef fish assemblage, while accounting for habitat. Modelled biological responses were abundances and diversity indices calculated at different levels of the assemblage. Significant effects were found for many of these metrics. In addition to PERMANOVA, univariate models provided more insight into the magnitude and direction of effects. The most sensitive metrics were related to large species and species targeted by fishing. These results may be used to choose the metrics that are more suitable as community-based indicators of MPA impact in the perspective of monitoring programs.
\end{abstract}

Keywords: impact assessment, marine protected area, ecological indicator, permutational multivariate analysis of variance, multivariate regression trees, reef fish assemblage, northwestern Mediterranean

\title{
1. Introduction
}

* Corresponding author. Tel.: + 33-4-68-66-21-90; fax: + 33-4-68-50-36-86

E-mail address: joachim.claudet@ifremer.fr 
Over the last 15 years, most coastal fish resources have been overexploited (Lauck et al., 1998; Castilla, 2000), raising doubts about the long-term sustainability of certain fisheries (Murray et al., 1999; Pauly et al., 2002). In addition, fish habitat has also been strongly altered by widely used fishing gears such as trawls and dredges, resulting in reduced seabed complexity and removal of macrobenthic organisms that provide shelter for others (Sumaila et al., 2000). Marine Protected Areas (MPAs) are increasingly considered in coastal areas as an instrument to preserve vagile fauna and habitat from detrimental effects of fishing (Francour et al., 2001; Halpern, 2003; Sainsbury and Sumaila, 2003). The use of anti-trawling artificial reefs along the boundaries of several French, Italian and Spanish MPAs has proved to be an effective way of excluding non-selective towed fishing gears which bear detrimental effects on habitats (Harmelin, 2000). It is anticipated that MPAs, and in particular no-take reserves be more effective as a fishery and conservation tool for organisms that have relatively sedentary adult life stages and exhibit larval dispersion, enabling biomass exportation to surrounding areas (Nowlis and Roberts, 1999; Chiappone and Sealey, 2000). There are many documented examples where fished species have benefited from reserve establishment, in particular through increases in mean size and abundance (for reviews, see Roberts and Polunin, 1991; Dugan and Davis, 1993; Rowley, 1994; Bohnsack, 1998; Halpern, 2003). But MPA effects may be diverse in direction and magnitude (Halpern and Warner, 2002). Hence, effects depend on species and timing with respect to reserve establishment (Mosqueira et al., 2000). Sometimes, biological responses (abundance, density, biomass, average size, and diversity of organisms) either consistently increased within the reserve over time (Russ and Alcala, 1996), showed little change over time (Denny and Babcock, 2004), or initially rose but then fell back to original levels (Dufour et al., 1995). Biological responses to protection are also highly variable among fish taxa, but in general species targeted by exploitation are affected in a more positive way than non-target species (Côté et al., 2001), even in the case of recreational fishing (Westera et al., 2003). Large-bodied species also respond more to protection, irrespective of their fishery status (Mosqueira et al., 2000). Most non-target species appear either not to respond to protection (Rakitin and Kramer, 1996) or to respond negatively by showing reduced abundances, perhaps in response to greater predator pressure within reserves (McClanahan et al., 1999).

In spite of these indications, it would be premature to conclude that no-take reserves are always effective for fisheries management, because there are relatively few empirical studies, many of which are poorly designed (Russ, 2002), and even the reported increases in density within reserve borders can be slight (Sale et al., 2005). Attempts to detect explained and predicted effects of MPAs should be based on statistical tests that distinguish between natural variability and the influence of management (Allison et al., 1998; Fraschetti et al., 2002; Benedetti-Cecchi et al., 2003). Despite many empirical studies on reserves, only a few included data collected before and after reserve establishment (Willis et al., 2003), which are the most appropriate for investigating the impact of reserve establishment. Note however that, if controls are numerous enough to allow an asymmetric 
comparison with the protected site, this impact can also be detected through "after data" (ACI, After Control Impact) (Glasby, 1997). In addition, few studies account for spatial and temporal variabilities of species, linked to environmental and biological factors other than MPA status (García-Charton and Pérez-Ruzafa, 1999). Fish populations usually exhibit variable degrees of spatial and temporal fluctuation in different parts of the habitat in which they occur. Hence, habitat structure often explains a substantial proportion of the observed variation in fish abundance (García-Charton and PérezRuzafa, 1999; García-Charton et al., 2000; Ferraris et al., 2005) and if the experimental design fails to capture this variability, any observed differences in fish assemblages may be confounded by differences in habitat (Westera et al., 2003).

An additional problem for studying MPA effects at the fish assemblage level is that most multivariate methods do not test for the presence of interactions and do not measure the magnitude of temporal changes in spatial differences (Clarke, 1993; Underwood and Chapman, 1998). Besides, multivariate analysis of variance requires assumptions about correlations between pairs of variables, assumptions that are rarely met in ecological data sets (Johnson and Field, 1993). Recent developments of permutational multivariate analyses of variance (Anderson, 2001a) could help to overcome these problems.

Explicit objectives and monitoring aimed at determining if objectives are met is essential to MPA success (Allison et al., 1998; Claudet and Pelletier, 2004). Monitoring programs provide data for management decisions through the computations of indicators to evaluate progress in conservation programs (Olsen, 2003). Provision of indicators addressing the range of management objectives is needed for integrated coastal management (Belfiore, 2003). These indicators are used for evaluating effects of interest with respect to management, and for communicating these results to managers (Linton and Warner, 2003). They must be tailored to particular uses and contexts in both scale and content (Dahl, 2000). Potential ecological indicators can be assessed through their relevance (i.e. the link with the question used) and their effectiveness (which encompasses the issues of precision, accuracy and statistical power) (Nicholson and Fryer, 2002). Many metrics have been used for assessing MPA effects on fish assemblages (for review, see Pelletier et al., 2005), the most frequently used being abundance, biomass, diversity indices and mean size. Pelletier et al. (2005) estimated the relevance and effectiveness of these metrics based on published studies. They showed that in many instances, the use of these metrics led to statistical results that were not significant. For example, the overall species richness of the fish assemblage did not appear to be sensitive to MPA status in the reviewed studies (as also indicated by Russ (1985) and Harmelin et al. (1995)). Aside from metrics computed from biological responses encompassing several species or the whole fish assemblage, indicators may be constructed with respect to individual species. The concept of indicator species has been widely used in water management (Bain et al., 2000), but more rarely in marine ecology (Mouillot et al., 2002; Sosa-López et al., 2005). An indicator species is expected to be abundant throughout the studied area and should be easy to sample (Linton and Warner, 2003). Using a large 
variety of indicator species could provide fine-grained information (Kremen, 1992). To avoid selecting indicator species on expert opinions, intuition and anecdotal information (Saetersdal et al., 2005), Dufrêne and Legendre (1997) developed a flexible and asymmetrical approach based on empirical data to identify indicator species. This method is based on species' specificity and fidelity, combining species' relative abundance and its frequency of occurrence in a group of sites or transects.

In the present study we were interesting at assessing the effects of a no-take marine reserve on the fish assemblage in a Mediterranean ecosystem. Because we were aiming at an evaluation at the assemblage level, while accounting for the assemblage structure, we analysed all data together, and applied multivariate approaches to several metrics pertaining to different groups of fish. To ensure that MPA effects were not confounded with other factors structuring spatial variability of fish, habitat characteristics were considered in the models. Finally, model results were interpreted using a method for identifying indicator species that could be relevant for monitoring and management purposes.

\section{Materials and methods}

\subsection{The studied system}

Located in the French northwestern Mediterranean, the Côte Bleue Marine Park (CBMP) was established in 1983. Its primary aim was to protect marine biodiversity, to favour social and economic activities linked to the sea, especially fisheries, and to promote public education and scientific research. The CBMP comprises two effectively enforced no-take reserves: Carry ( 85 ha), established in 1983, and Couronne (210 ha), established in late 1995 (Fig. 1). In addition to the reserves, two kinds of artificial reefs, for protection against illegal trawling, and for biomass production, were immersed within the park since 1983, several of them being set at the border of the two reserves to ensure trawl exclusion. In both Carry and Couronne MPAs, fishing, harvesting, scuba diving, anchoring and dredging are forbidden. Compliance is high because the two MPAs were established with the support of users. Commercial and recreational fishing occurs outside the MPAs (Francour et al., 2001). The commercial fishery uses gill nets set on the bottom. They are on average $1.5 \mathrm{~m}$ high, and 2500 to $3500 \mathrm{~m}$ long. Gill net is well suited for small inshore bottoms with chequered patterns of Posidonia oceanica meadows, rocks and sand. There are 40 fishing boats and the number of fishers has remained stable over the last 20 years. The recreational fishery comprises 60 sailors on average, mainly uses handline, and targets Labridae and Sparidae. Aside from these fisheries, there is some trawling activity in the vicinity of the CBMP, and occasionally some illegal trawling occurs in the inshore area, explaining immersions of anti-trawling artificial reefs. The aim of this study was to test whether or not the Couronne MPA together with bordering artificial reefs is effective in restoring local fish assemblages. 
Fish assemblages of rocky coasts and artificial reefs in the northwestern Mediterranean have been the focus of several studies (Bell and Harmelin-Vivien, 1982; Bell, 1983; Dufour et al., 1995; Harmelin et al., 1995; Harmelin, 1999; Charbonnel et al., 2000; Jouvenel and Pollard, 2001; Charbonnel et al., 2002). Rocky reef fish assemblages are found to be characterised by the dominance of three families, namely the Labridae (Labrus and Ctenolabrus), the Sparidae (Diplodus) and the Serranidae (Serranus). Many of these species are territorial, with limited home ranges and low interannual variations. Sedentary planktivorous fish are also found in the assemblages with Pomacentridae in the shallower areas and Serranidae (Anthias anthias) in the deepest ones. Species movements may be in groups but are always restricted in space. They are mainly dictated by seasonal patterns and water temperature. A few pelagic species are also observed in these assemblages during summer, e.g. Carangidae, Clupeidae and some Sparidae species (Sparus aurata and Dentex dentex).

\subsection{Sampling design and data collection}

Surveys were conducted at the end of summer during three years: before MPA establishment, in 1995, and after, in 1998 and 2001. Two locations were considered in this study: one Within the Reserve (WR) boundaries and one Outside the Reserve (OR). Two sites per location were chosen in the same range of depth (between 14 and $18 \mathrm{~m}$ ) (Fig. 1). Within the reserve, an additional site was sampled at larger depths (between 24 and $26 \mathrm{~m}$ ) to study the spatial variation and the effect of depth upon fish abundance.

Underwater Visual Census (UVC) monitoring techniques provide qualitative and quantitative surveys with a limited impact on the ecosystem, and are therefore particularly suited for marine reserves (Harmelin et al., 1995; Ciriaco et al., 1998). Twelve $20 \mathrm{~m}$-long transects were sampled by scuba divers in each site. Divers swam one way for 8 to 10 minutes along each transect, identifying and recording the number and size of each fish species observed within a distance of $2.5 \mathrm{~m}$ on each side of the transect. Fish sizes were estimated according to three size groups (small, medium, large); the total fish abundance of a species being the sum of the abundances per size group. For each species, size groups were defined using $33 \%$ and $66 \%$ percentiles of the maximum size generally observed in the region. All fish seen were recorded but pelagic species (Sardina pilchardus) and notoriously cryptic species (e.g. Gobiidae, Bleniidae, Tripterygiidae) were excluded from the analyses. Sampling methodology and divers remained the same each year to minimise biases inherent in UVC (Kulbicki, 1998; Edgar et al., 2004a). The position of the transects was the same for each year. Under the hypothesis that habitat did not change in the surveyed years, we thus assumed that interannual variations in fish assemblage were not caused by habitat changes.

Although the surveyed sites were very similar, environmental data were collected to assess small-scale spatial variability. For each transect, the complexity of the substratum was coded into three classes: 1 for smooth bottoms, 2 for smooth bottoms with a few blocks lower than $50 \mathrm{~cm}$ and not 
suitable for shelter, 3 for bottoms with more blocks, some higher than $1 \mathrm{~m}$, and a lot of refuges. The percent linear cover of Posidonia oceanica was estimated along each transect after fish counts. Divers also recorded the depth at the beginning and at the end of each transect.

\subsection{Analysis of data}

We were interested in assessing whether the Couronne MPA together with bordering artificial reefs is effective at restoring local fish assemblages. This evaluation was carried out at the fish assemblage level and should thus account for assemblage structure. In order to do so, we used multivariate techniques that are suited for ecological data. In a second step, we ensured that observed spatial variation was due to MPA effects and not to other factors structuring spatial variability of fish, by considering habitat characteristics together with MPA design in a single model. Model results were interpreted using a method for identifying indicator species that could be relevant for monitoring and management purposes.

\subsubsection{Modelling spatial and temporal variations between within and outside the MPA}

Fish abundance was modelled as a function of Location, Year, and Site. All three factors were treated as fixed, the Site factor being nested within the Location factor, factor Year being crossed with the two other factors. For each surveyed year, data were collected at two locations, two sites within each location and $n=12$ transects within each site, leading to a total of 144 observations in the data set. Because depth strongly structures the spatial distribution of fish, data from the deeper site WR3 within the MPA was not considered in the present model (but see section 2.3.2), in order to maximise the the probability of detecting an impact of MPA (Benedetti-Cecchi, 2001). To estimate synergisms and antagonisms among the effects of the different factors investigated (Underwood, 1981), the model included all combinations of the factor levels. Given the design, the linear algebraic model thus wrote:

$$
\mathrm{X}_{i j k z}=\mu+\mathrm{Ye}_{i}+\mathrm{Lo}_{j}+\mathrm{Ye} \times \mathrm{Lo}_{i j}+\mathrm{Si}(\mathrm{Lo})_{k(j)}+\mathrm{Ye} \times \mathrm{Si}(\mathrm{Lo})_{i k(j)}+e_{z(j i k)}
$$

where $X_{i j k z}$ represents the set of abundances observed at the $z$ th replicate $(z=1,2, \ldots, 12)$ of the $k$ th level of the nested factor Site $(\mathrm{Si})$ in the $j$ th level of the factor Location (Lo) crossed with the $i$ th level of the factor Year (Ye). $\mu$ represents the overall mean abundance vector. $\mathrm{Ye}_{i}$ represents the effect of the $i$ th level of the factor Year $(i=1,2,3)$; $\operatorname{Lo}_{j}$ denotes the effect of the $j$ th level of the factor Location $(j=1,2) ; \mathrm{Si}(\mathrm{Lo})_{k(j)}$ represents the effect of the $k$ th level of the nested factor Site in the $j$ th level of the factor Location $(k=1,2)$; $\mathrm{Ye} \times \operatorname{Lo}_{i j}$ and $\mathrm{Ye} \times \mathrm{Si}(\mathrm{Lo})_{i k(j)}$ correspond to the interaction effects of the factors Year and Location and of the factors Year and Site; finally, $e_{z(i j k)}$ represents the error term associated with each observation. All factors being fixed, the term used for denominator mean square in the F-ratio was thus always the residuals for all terms in the model. 
With Before-After-Control-Impact data, the consequences of the MPA on the fish assemblage may be studied from differences in the change of fish species biological responses (e.g., abundance, richness, diversity) inside the MPA location from before to after its establishment compared with such changes from before to after in the control location (sensu Underwood, 1993). Under this model, an effect of the reserve on the fish assemblage is evidenced if the interaction term between Year and Location is statistically significant. Such differences in biological responses across years and between inside and outside the MPA (termed inside/outside differences from this point onwards) were interpreted by pair-wise comparisons conducted on these interaction terms. Differences between sites over years in a given location (i.e., a significant Year $\times$ Site(Location) interaction) do not interfere with the MPA effects. These differences could be due to small scale variability in the assemblages of fish. The presence of significant higher-order interactions warns that the experimental treatments do not operate independently, in any combinations (Underwood, 1981).

The observed fish assemblage comprised 40 species (Appendix 1). In order to analyse how the fish assemblage responds to the MPA-artificial reef system, models were constructed for sets of abundance indices calculated at several levels and for several components of the fish assemblage (see Appendix 1): i) abundance per species for the whole fish assemblage; ii) abundance per observed size group (small, medium and large); iii) abundance per species for species grouped by species size; iv) abundance per species for species groups based on the species' fishing value; and v) abundance per species for species groups based on mobility. Species size groups were based on the minimum and maximum lengths generally observed for each species in the northwestern Mediterranean, i.e. $8-20 \mathrm{~cm}$, $20-30 \mathrm{~cm}$ and $30-200 \mathrm{~cm}$. For fishing value, three groups of species were considered: unfished species, species with low fishing value, and species with medium to high fishing value. Regarding mobility, we distinguished mobile species and sedentary species; mobile species including demersal species displaying horizontal movements and possibly vertical movements, and sedentary species including benthic species and species that move only marginally, both horizontally and vertically.

Unfortunately, distributions of abundances per fish species are usually highly skewed and contain many zeros. Conventional multivariate inferential methods such as MANOVA are not appropriate for this kind of data. We thus used the permutational multivariate analysis of variance (PERMANOVA), initially called NPMANOVA (Anderson, 2001a; McArdle and Anderson, 2001). This method analyses the variance of multivariate data explained by a set of explanatory factors on the basis of any distance or dissimilarity measure of choice, thereby allowing for a wide range of empirical data distributions. The method provides $P$-values by permutations, so that effects linked to each factor or interaction between factors may be tested in a more robust way than with MANOVA. To perform the PERMANOVA, the FORTRAN computer program DISTLM4 was used (Anderson, 2004b). In the models, fish abundance data were log-transformed. We used the binomial deviance dissimilarity that is appropriate for this kind of empirical distributions (Anderson and Millar, 2004). Each term in the model was tested through permutation tests based on 4999 permutations of residuals 
under a reduced model to obtain $P$-values. This permutation method is generally thought to be best suited because it provides the best statistical power and the most accurate Type I error (Anderson and Legendre, 1999). When significant at the 0.05 level, the $\mathrm{Ye} \times \mathrm{Lo}_{i j}$ interaction term was investigated through a posteriori pair-wise comparisons using 4999 random permutations to obtain $P$-values. Because multiple multivariate interactions are difficult to visualize, they were projected in the twodimensional plane generated by the first two axes obtained from discriminant analyses conducted separately for each year to discriminate fish abundances observed within the reserve from those observed outside the reserve. This way, within-location variabilities can be visually compared and tested. In addition, the correlation between the fish species and the axis indicate which species are determining in explaining differences between locations, i.e. which species exhibit spatial differences in abundance due to MPA.

In practice, discriminant analyses were achieved using the CAP software (Anderson, 2004a) which calculates a canonical analysis on the principal coordinates based on any symmetric distance matrix, including a permutation test (Anderson, 2004a). We used the same data transformation and dissimilarity measure for CAP and for PERMANOVA, i.e. abundance data were log-transformed, the distance measure used was the binomial deviance dissimilarity and tests relied on 4999 permutations.

Previous multivariate analyses yield a test of the MPA effect and allow to identify species that are closely linked to these effects. Furthermore, we were also interested in analysing the effect of the MPA on diversity metrics. This was addressed through univariate analyses. We first modelled the abundance of two fished species with high fishing value and one species with low fished value. We selected species encountered in more than $50 \%$ of the transects across the factors of interests (see Appendix 1) namely Coris julis, Serranus cabrilla, and Symphodus doderleini. We then modelled overall fish abundance, species richness and the Shannon-Wiener diversity index. For each of these variables, two analyses were carried out: one considering all fish and the other considering only large fish, because large fish usually respond more to protection (Mosqueira et al., 2000). Analyses were conducted using a permutation tests realised using the DISTLM4 software (Anderson, 2004b) with 4999 random permutations. In the models, only abundance variables were log-transformed. Unlike multivariate analyses described above, we used a Euclidean distance in the univariate models. We particularly tested the $\mathrm{Ye} \times \mathrm{Lo}_{i j}$ interaction term from a posteriori pair-wise comparisons, based on 4999 random permutations under a 0.05 significance level. Boxplots were used to illustrate mean abundances per Location and Year for each modelled variable.

\subsubsection{Incorporating the influence of depth and habitat in the assessment of MPA effects}

Models described in the previous subsection do not account for environmental variables such habitat and depth, measured as part of the study design. Depth issues were avoided by excluding a site that was deeper than the others. 
A first appraisal of the relationships between species abundance and environment is provided by modelling the abundances of all species as a function of three environmental covariables: mean depth, percentage linear cover of Posidonia oceanica, and substrate complexity. This was achieved by a multivariate analysis of covariance. This analysis was carried out from the DISTLM4 software. In the model, the distance measure was the binomial deviance dissimilarity and 4999 permutations were done for the tests.

In a second step, only significant environmental covariables and factors allowing the evaluation of MPA effects on the set of abundances per species were included as explicative variables of fish abundance data per species and per transect. In this purpose, we used Multivariate Regression Trees (MRT) (De'ath, 2002). This multivariate discrimination technique constructs a hierarchical tree through successive dichotomies of the set of observations. It was used to build hierarchical groups of observations to analyse which of the protection or the environment affected more the fish assemblages. Splits and clusters are characterised by values and conditions on explicative variables. Fish abundance data were log-transformed. The MRT technique does not require any assumptions about the form of the relationships between observations and explicative variables. Trees were pruned by cross-validation using the minimum rule of Breiman et al. (1984). These analyses were done using the mvpart package of the R statistical software (Therneau et al., 2004). Two MRT were calculated from log-transformed abundance data concerning: i) the four sites previously used in the PERMANOVA (WR1, WR2, OR2 and OR2), and ii) the four previous sites and in addition the deeper site within the MPA, WR3, (Fig. 1), where the resulting number of sampling units was 180 . The site WR3 was included to analyse the respective influence of depth and protection upon fish assemblages. In each case (with and without WR3) two MRT were calculated, one with the fish abundance data of all sizes and one only with large fish. Explanatory variables were the three factors Year, Location, Site, and the three environmental variables (percentage linear coverage of Posidonia oceanica, substrate complexity and average depth). Two fish species that display schooling behaviour were excluded from MRT calculations (Boops boops and Chromis chromis).

\subsubsection{Identifying indicator species}

In a last step, the MRT were used to identify indicator species. Tree leaves, i.e. clusters corresponding to a given split were characterised by species using the Indicator Value (IndVal) method (Dufrêne and Legendre, 1997). With this approach, indicator species characterise a cluster of observations corresponding to a given leaf of the tree if it is simultaneously abundant and frequent in the group compared to the whole set of observations. The index used to identify indicator species is the product of relative abundance and relative frequency of occurrence. It is maximum for a given cluster when the species is found in all observations in this cluster and is not encountered in other clusters. The statistical significance of a species as an indicator at the 0.05 level was evaluated using a randomization procedure. Calculations were done using the IndVal 2.0 FORTRAN computer program. 


\section{Results}

\subsection{Modelling spatial and temporal variations within and outside the MPA}

PERMANOVA of the fish abundances per species showed a significant multivariate interaction between factors Year and Location whatever fish size (Table 1); thereby indicating an MPA effect. There were no initial differences in abundances between locations (within versus outside reserve) before MPA establishment, in 1995 (Table 2). Application of the discriminant analysis to abundance of large fish showed that the classification in two groups was not significant in $1995(P=$ 0.5456 ; the proportion of classification in the correct cluster was only 58\%), confirming the absence of inside/outside differences in the assemblages of large fish before MPA establishment.

To the exception of small fish individuals, inside/outside differences in species abundance became significant after MPA establishment, abundances being on average higher within the reserve (Appendix 2). These differences were more significant for large fish than for medium-sized fish. Results of discriminant analyses of the abundance of large fish illustrated that these differences appeared after 1995 (Fig. 2). A similar, although less marked, trend could be observed for mediumsized fish and for all fish (not reported here). After MPA establishment, i.e. in 1998 and 2001, the classification of fish abundance data into two groups became significant ( $P=0.0002$ in both cases). For both years, $83 \%$ of observations of the original 48 were correctly classified. In 1998 (results not reported on Fig. 2), only species positively correlated with the canonical axes showed high correlations $(>0.5)$, namely large fish of the commercial species Serranus cabrilla, Coris julis, Ctenolabrus rupestris, Symphodus doderleini and Symphodus mediterraneus. In 2001, high positive correlations with the canonical axes were observed for large Diplodus sargus, Diplodus vulgaris, Symphodus melanocercus, Symphodus tinca, and again Serranus cabrilla, Coris julis, Ctenolabrus rupestris and Symphodus doderleini; all being commercial species. In both cases, large positive correlations indicate significantly larger abundances for these species within the MPA. However, negative correlations indicating higher abundances outside the reserve were observed for Spicara maena and Chromis chromis. Between sites variability was only significant for small fish outside the MPA in 2001 (pair-wise comparison, $P=0.0124$ ).

In the case of species size groups, PERMANOVAs showed a significant Year $\times$ Location interaction for all groups (Table 3). Inside/outside differences were significant across all years only for small species (Table 2), abundances being on average always higher within the MPA (Appendix 2). For medium-sized species, differences between locations became significant after MPA establishment, and only in 2001 for large species (see Appendix 2 for mean abundances). Between-sites differences could be evidenced for large and medium-sized fish species. These small-scale differences were significant within the reserve in 2001 for large species (pair-wise comparison, $P=0.0010$ ) and within 
the reserve in 1998 and outside the MPA in 2001 for medium-sized species (pair-wise comparison, $P$ $=0.0320$ and $P=0.0010$, respectively).

There was no significant Year $\times$ Location interaction for unfished species (Table 4). The abundances of unfished species were different between years (Table 4) and only significantly different between 1998 and 2001 (pair-wise comparison, $P=0.0196$ ). For fished species, PERMANOVAs produced a significant Year $\times$ Location interaction. The abundances of species with low fishing value were significantly different between locations across all years. Significant inside/outside differences occurred only after MPA establishment for species of medium to high fishing value and became more significant over the years (Table 2). Across all years, the sites inside the reserve showed on average, lower abundances of species with low fishing value (Appendix 2). On the opposite, species with medium to high fishing value were, on average, more abundant inside the reserve. For these species, there were significant between-sites difference outside the MPA in 2001 (pair-wise comparisons, $P=$ $0.0018)$

PERMANOVAs conducted on the abundance per species when species were grouped by mobility showed a significant interaction for both mobile and sedentary species (Table 5). Inside/outside differences were significant across all years, for these species, except in 1995 where there were no differences for mobile species (Table 2). For both groups of species, when inside/outside differences were significant, abundances were on average higher inside the MPA (Appendix 2). Significant between-sites differences occurred only for sedentary species in 1998 within the MPA (pair-wise comparison, $P=0.0140$ ) and in 2001 outside the MPA (pair-wise comparison, $P$ $=0.0060)$.

Permutational univariate ANOVAs on overall abundance, richness and diversity showed a significant Year $\times$ Location interaction for all metrics considered (Table 6). Inside/outside differences were not significant before MPA establishment (Table 7). In 1998, differences between locations on overall abundance, richness and diversity, became significant only for large fish. In 2001, inside/outside differences in overall abundance, species richness and diversity were all significant whether considering all or large fish. When differences were significant, the value of the metric was always larger within the MPA (Fig. 3), except for the diversity index which was higher outside the MPA in 1998 (Fig. 3). However, diversity became lower outside the MPA in 2001. It is interesting to note that for large fish, inside/outside differences were significant from 1998 and increased in 2001. In 1995, total abundance and diversity displayed significant between-sites differences, respectively inside the MPA (pair-wise comparison, $P=0.0434$ ) and outside the MPA (pair-wise comparison, $P=$ 0.0078). In 2001, between-site differences were significant outside the MPA for total abundance, species richness, overall diversity and diversity of observed large fish (pair-wise comparison, respectively $P=0.0158 ; P=0.0048 ; P=0.0004 ; P=0.0012$ ).

The permutational univariate ANOVAs of the abundance of two species of high fishing value, Coris julis and Serranus cabrilla, and one species with low fishing value, Symphodus doderleini 
revealed a significant Year $\times$ Location interaction for the three species (Table 8). The interaction was significant for total species abundance and for the abundance of large fish. In all cases, inside/outside differences were not significant before MPA establishment (Table 7). In 1998, all inside/outside differences were significant, except for total abundance of Coris julis. Note that the inside/outside difference was less marked for Symphodus doderleini. In 2001, inside/outside differences were still significant for Serranus cabrilla and Coris julis (and indeed more significant than in 1998 for total abundance of Coris julis), whereas they were not any longer significant for Symphodus doderleini. These differences corresponded to higher abundances inside the MPA compared to outside the MPA (Fig. 4). Results were similar for all observed Symphodus species (eight species), for both total and large fish abundance. Note that between-site differences were significant for Coris julis outside the MPA in 2001 (pair-wise comparison, $P=0.0026$ ).

\subsection{Joint effects of MPA, depth and habitat on the fish assemblage}

A multivariate nonparametric analysis of covariance was performed on the whole fish assemblage to explore the relationship between fish abundance and a set of the three environmental variables, i.e. mean depth, complexity, and linear percentage cover of Posidonia oceanica). These covariables were found to have a significant effect on fish abundance $(P=0.002)$. However, accounting for these covariables including Year, Site and Location factors in the model did not change the significance of the interactions Year $\times$ Location and Year $\times$ Site(Location); respectively $P=0.002$ and $P=0.0118$.

MRTs were calculated for abundance per species, in the case of total abundance and abundance of large fish, using previous environmental variables (depth, complexity, percentage linear cover of Posidonia oceanica), and factors Year, Location, and Site, as explanatory variables. In both cases, MRTs were calculated considering or not data collected in the deeper site WR3. Although results were valid in the four cases (total/large fish abundance combined with/without R3), they were only reported for abundance of large fish considering WR3, for sake of concision (Fig. 5). The first split separated observations within the MPA from observations without the MPA in three cases out of four, the latter corresponding to total abundance with data from site R3. In all three cases, the second split, whether within or outside the MPA, separated 1995 from 1998 and 2001 (i.e., the year before the MPA establishment from the years after). To analyse whether the first split of these trees was indicating a habitat effect or a reserve effect, additional trees were computed using a composite factor for the interaction between factors Year and Location (six levels, e.g. WR.1995). In this case, the first split separated observations within the MPA after its establishment from observations of both locations before MPA establishment and observations from outside the MPA. We thus concluded that the first split indicated a reserve effect. All following splits were similar to the ones obtained in other trees. In the fourth case, i.e. for total abundance with data from site WR3, the first split separated this 
site from all the others. In the second split, sites were separated depending on whether they were within or outside the MPA. Later splits were similar to the three other cases. Transects within WR3 were distinguished by Posidonia oceanica cover (with a percent level of discrimination of 42.5). In the MRT obtained for the abundance of large fish considering data from site WR3 (Fig. 5), abundances after MPA establishment (1998 and 2001) within MPA were distinguished according to depth. At shallower depths $(<21.5 \mathrm{~m})$, abundances differed between 1998 and 2001. At larger depths $(\geq 21.5 \mathrm{~m})$, Posidonia oceanica cover explained differences between abundances obtained at distinct transects. Thus, habitat variables were only discriminant after MPA establishment and within the MPA, and differences in abundance over years were more marked in shallower depths than in larger depths.

\subsection{Indicator species}

Indicator species were searched for the MRT reported in Fig. 5. Two groups of species were indicators of the first split, i.e. separating within from outside MPA locations, irrespective of other factors: Apogon imberbis was specific of observations outside the MPA (i.e. being more abundant and more frequent in these transects, group III in Fig. 5). The Serranidae Serranus cabrilla and the Labridae Coris julis and Ctenolabrus rupestris were specific of observations inside the MPA (group II in Fig. 5). These three species had still significant indicator values after the MPA establishment (i.e. after other splits) but these values were maximum for group II. Outside the MPA, the Labridae Symphodus doderleini and Symphodus roissali were indicator species of the year before MPA establishment (group F in Fig. 5). Within the MPA, the Sparidae Sarpa salpa and the Labridae Symphodus tinca were indicator species for years after MPA establishment, whatever habitat characteristics (group IV in Fig. 5). No indicator species was found for shallower depths; whereas at larger depths, the Scorpaenidae Scorpaena porcus and the Mullidae Mullus surmuletus were significant indicator species (group V in Fig. 5). The Serranidae Anthias anthias and the Sparidae Diplodus vulgaris and Diplodus sargus were specific of MPA, after its establishment, but only at larger depths and where the percent cover of Posidonia oceanica was low (group B in Fig. 5). Species of group A were distinguished from those in group B only by a higher percentage linear cover of Posidonia oceanica; these were namely: the Scorpaenidae Scorpaena scrofa and Scorpaena notata, the Centracanthidae Spicara maena and the Labridae Labrus merula and Labrus viridis.

\section{Discussion}

\subsection{Assessment of MPA impact}

In general, results showed significant inside/outside differences in the multivariate abundance structure of fish assemblages, across years, for all groups of fish or species considered, except for 
unfished species. Multivariate interactions were also significant when environmental covariables were accounted for in the models. These results were confirmed and exemplified by significant univariate differences between locations across years for total abundance, species richness and diversity for the abundances of the three species analysed.

Before MPA establishment, only the groups of small species, species of low fishing value and sedentary species already displayed significant inside/outside differences in abundance. Only species with low fishing value had on average higher abundances outside the MPA. The majority of sedentary species were small species (41\%), whereas mobile species were mostly large species (39\%). Thus, initial inside/outside differences could be explained by small species, with higher abundances inside the reserve. These species are usually sedentary with limited movements. Habitat preferences and/or natural variability could explain these spatial differences, even if habitat variables considered in the study did not allow to test this hypothesis. In 1995, indicator species could be identified only outside the MPA. The analysis of the fish assemblage status before MPA establishment is particularly important as it provides the baseline information for future monitoring and assessment (Edgar et al., 2004).

After MPA establishment, changes in spatial patterns could be clearly evidenced (Fig. 2). In 1998, inside/outside differences in abundance were significant for all groups considered, except for small fish and surprisingly for large species. These corresponded to increased abundances within the MPA. The magnitude of the response to MPA establishment was not clearly related with fishing value at this early stage of restoration (i.e. three years after MPA establishment). At the fish assemblage level, inside/outside differences were more marked for metrics (total abundance, species richness and diversity) calculated from large fish only. At the species level, all metrics responded to MPA establishment, except for total abundance of Coris julis, through increasing abundances within the MPA. From 1998 onwards, many species belonging to almost all the families encountered in the study were significant indicator species within the MPA, but no indicator species could be identified for a particular year (1998 or 2001); which in fact would not be desirable for an indicator of protection.

It is interesting to note that, six years after MPA establishment (in 2001), inside/outside differences were even more significant than in 1998, except for metrics computed from small fish only. The contrast between increased abundances of large and medium fish, and stable abundances of small fish shows that six years after MPA establishment, positive effects mostly pertain to larger sizes and larger abundances within the MPA. Effects linked to reproduction are thus not yet evidenced, at least not from this kind of data. Furthermore, there is still no clear link between fishing value of species and response to MPA establishment. Although differences in abundance of species with medium to high fishing value were more significant in 2001 than in 1998, this may rather be explained by demographic characteristics of species or changes in fishing patterns outside the MPA. This also explains why inside/outside differences became significant for Coris julis, an important target species for fisheries. At the fish assemblage level, all metrics (total abundance, species richness and diversity) 
displayed significant inside/outside differences six years after MPA establishment. At this scale, metrics based on large fish thus appeared as relevant indicators of MPA effect at an early stage of restoration, while metrics calculated from all fish may be appropriate for restoration effects in the medium term.

Beside these effects of the Couronne MPA, mean depth and substrate complexity had an influence on the distribution of the whole fish assemblage and on large fish. Percentage linear cover of Posidonia oceanica only had a structuring influence at depths deeper than $21.5 \mathrm{~m}$ and after 1995.

\subsection{Methodological aspects}

Studying MPA effectiveness by species or by taxa, as has been done in many articles, is important but not sufficient in an ecosystem-based perspective. Changes in the composition of the whole fish assemblage have to be assessed across MPAs boundaries. The permutational multivariate analysis of variance allowed the production of a diagnostic on the evolution of the entire fish assemblage with respect to MPA establishment. Unlike MANOVA, the method does not require assumptions about distributions. The variance can be partitioned across the relevant factors of interest and any model can be tested. This analysis is rarely used to study MPA efficiency (Willis and Anderson, 2003; Fraschetti et al., 2005) (see comments on these studies below).

PERMANOVA informs about the effects of the MPA on the fish assemblage but it cannot be used directly to monitor the magnitude and direction of effects per metric. Ordination techniques, such as discriminant analysis, can be used to test and visualize these effects. MRT cannot be used for hypothesis testing but are helpful to build a hierarchical structure of the environmental variables structuring fish assemblages. Beside it accepts quantitative variables and qualitative factors in the same analysis. MRT, together with IndVal may provide indicators of MPA status. Note that results obtained with the IndVal index were consistent and complementary with those obtained from the discriminant analysis.

In the case of persistent effects ("press impact"), as the effects caused by the establishment of a MPA on the fish assemblages are expected to be, the power of the statistical tests is not increased by an increase in the number of replicates, days or periods of sampling; but only by an increase in the number of locations of control and incidentally of impacted localities, if possible (Underwood \& Chapman, 2003). Consequently, the experimental design used here to assess the effect of the MPA should be improved in the further monitoring programs by raising the number of locations, even if still taking habitat variables as covariables in the analyses.

\subsection{Conservation aspects and indicators for management}


The positive effects seen in this study may not be generalised. For example, in the Mimiwhangata Marine Park (New Zealand), the snapper (Pagrus auratus), the most heavily targeted fish species in the region, showed no difference in abundance or size between the Marine Park and adjacent control areas (Denny and Babcock, 2004). Fraschetti et al. (2005), studying benthic assemblages, showed that most of the variables considered (i.e. substrate cover, number of taxa, and average abundance of the most common taxa) were not significantly different between the protected and unprotected areas. Protecting species requires prioritization. Indeed protection can improve abundances or sizes, but target species are very often predator species and thus there will be higher predation pressure on the preys inside the MPA, leading to changes in the fish assemblages (Francour, 1994; Pinnegar et al., 2000; Ashworth and Ormond, 2005). In the present study, notoriously cryptic fish species have been removed from the analyses, whereas MPAs could have potential negative impacts on them. Willis and Anderson (2003) showed that the sites inside the marine reserve contained, on average, lower densities of cryptic fishes than sites outside the reserve, which might be explained by effects of predators.

Defining groups of fish based on ecological or management criterion (e.g. commercial vs. non commercial species) can provide different but complementary information about the status of the fish assemblage. The availability of data by size group is also helpful to assess the effects of protection, MPAs being effective at various temporal scales across fish sizes. Increase in fish size could be a direct effect of the protection and this increase could have indirect effects on inter-population differences in the reproductive output among organisms for which fecundity is dependent on body size (Roberts and Polunin, 1991). Actually, in a stochastic simulation model, including a subpopulation of larger mean asymptotic body size resulted in less time spent at very small population sizes, which could reduce extinction risks (Kritzer and Davies, 2005).

An indicator is a metric that should be sensitive to the effect studied. Significant effects and their increased significance over time showed the sensitivity of the corresponding metrics to MPA establishment. From our results, relevant indicators could be at the species level, Serranus cabrilla, and to a lesser extent, Coris julis, since they display marked differences only three years after MPA establishment. However, it is also interesting to monitor species that may display less immediate effects such Symphodus doderleini. At the fish assemblage level, metrics computed on large fish are obviously good indicators of restoration in early stages, whereas metrics computed on all fish give a more holistic appraisal at later stages.

Indicator species that are characteristic of a combination of factors and environmental variables such as depth may be a valuable tool for managers (Pullin et al., 2004). The more the habitat characteristics will be recorded precisely, the more accurate the index value of indicator species will be. The purpose here is not to avoid regular surveys identifying all the species encountered, but to be able to record, between such comprehensive surveys, the abundances of indicator species of particular interest for MPA monitoring. This monitoring of indicator species will inform about MPA efficiency 
at a reasonable cost, and it does not require costly training of observers. Such simplified monitoring protocols have already been investigated in the CBMP. They consisted of randomly spaced catching operations of large individuals of three Serranid species considered as indicators of a reserve effect (Harmelin et al., 1995).

Here, we assessed the effects of the MPA in relation to fisheries goals (i.e. effects on fish abundances and sizes) and conservation goals (i.e. effects on species richness and diversity). But many other aspects could have been investigated such as socio-economic impacts of the reserve (Badalamenti et al., 2000; Carter, 2003; Rudd et al., 2003; Chee, 2004; Pelletier et al., 2005). Linkages between ecological and economic systems often give rise to direct and immediate feedbacks (Brown et al., 2001). Clearly, studies on MPAs have to be more and more multidisciplinary, and this cannot be done without a clear planning, monitoring and evaluation (Jameson et al., 2002; Hilborn et al., 2004), and more linked with policy and management (Alder et al., 2002; Fazey et al., 2005). 


\section{Acknowledgements}

The authors wish to thank the Côte Bleue Marine Park staff. The surveys were supported by funds from the Direction Régionale de l'Environnement Provence-Alpes-Côte-d'Azur and from the Agence de l'Eau Rhône-Méditerranée. This study is part of the Programme Systèmes Côtiers et Lagunaires (SysCoLag), funded by the Region Languedoc-Roussillon (Contrat de Plan Etat/Région 2000-2006), and of the Liteau-AMP project funded by the French Ministry for Ecology and Sustainable Development. This work was made possible through joint financial support from SysCoLag and from IFREMER funding for the PhD thesis of Joachim Claudet.

\section{References}

Alder, J., Zeller, D., Pitcher, T.J., Sumaila, U.R., 2002. A method for evaluating marine protected area management. Coastal Management 30, 121-131.

Allison, G.W., Lubchenco, J., Carr, M.H., 1998. Marine reserves are necessary but not sufficient for marine conservation. Ecological Applications 8, S79-S92.

Anderson, M.J., 2001a. A new method for non-parametric multivariate analysis of variance. Austral Ecology 26, 32-46.

Anderson, M.J., 2001b. Permutation tests for univariate or multivariate analysis of variance and regression. Canadian Journal of Fisheries and Aquatic Sciences 58, 626-639.

Anderson, M.J., 2003. DISTLM forward: a FORTRAN computer program to calculate a distancebased multivariate analysis for a linear model using forward selection. Department of Statistics, University of Auckland, New Zealand.

Anderson, M.J., 2004a. CAP: a FORTRAN computer program for canonical analysis of principal coordinates. Department of Statistics, University of Auckland, New Zealand. 
Anderson, M.J., 2004b. DISTLM v.4: a FORTRAN computer program to calculate a distance-based multivariate analysis for a linear model. Department of Statistics, University of Auckland, New Zealand.

Anderson, M.J., Legendre, P., 1999. An empirical comparison of permutation methods for tests of partial regression coefficients in a linear model. Journal of Statistical Computation and Simulation 62, 271-303.

Anderson, M.J., Millar, R.B., 2004. Spatial variation and effects of habitat on temperate reef fish assemblages in northeastern New Zealand. Journal of Experimental Marine Biology and Ecology 305, 191-221

Anderson, M.J., ter Braak, C.J.F., 2003. Permutation tests for multi-factorial analysis of variance. Journal of Statistical Computation and Simulation 73, 85-113.

Ashworth, J.S., Ormond, R.F.G., 2005. Effects of fishing pressure and trophic group on abundance and spillover across boundaries of a no-take zone. Biological Conservation 121, 333-344.

Badalamenti, F., Ramos, A.A., Voultsiadou, E., Sánchez-Lizaso, J.L., D'Anna, G., Pipitone, C., Mas, J., Ruiz-Fernandez, J.A., Whitmarsh, D., Riggio, S., 2000. Cultural and socio-economic impacts of Mediterranean marine protected areas. Environmental Conservation 27, 110-120.

Bain, M.B., Harig, A.L., Loucks, D.P., Goforth, R.R., Mills, K.E., 2000. Aquatic ecosystem protection and restoration: advances in methods for assessment and evaluation. Environmental Science and Policy 3, S89-S98.

Belfiore, S., 2003. The growth of integrated coastal management and the role of indicators in integrated coastal management: introduction to the special issue. Ocean \& Coastal Management 46, 225-234.

Bell, J.D., 1983. Effects of depth and marine reserve fishing restrictions on the structure of a rocky fish assemblage in the north-western Mediterranean Sea. Journal of Applied Ecology 20, 357369.

Bell, J.D., Harmelin-Vivien, M., 1982. Fish fauna of French Mediterranean Posidonia oceanica seagrass meadows. 1. Community structure. Tethys 10,337-347. 
Benedetti-Cecchi, L., 2001. Beyond BACI: optimization of environmental sampling designs through monitoring and simulation. Ecological Applications 11, 783-799.

Benedetti-Cecchi, L., Bertocci, I., Micheli, F., Maggi, E., Fosella, T., Vaselli, S., 2003. Implications of spatial heterogeneity for management of marine protected areas (MPAs): examples from assemblages of rocky coasts in the northwest Mediterranean. Marine Environmental Research $55,429-458$.

Bohnsack, J.A., 1998. Application of marine reserves to reef fisheries management. Australian Journal of Ecology 23, 298-304.

Breiman, L., Friedman, J.H., Olshen, R.A., Stone, C.J., 1984. Classification and regression trees. Chapman \& Hall, Belmont, California, USA.

Brown, K., Adger, W.N., Tompkins, E., Bacon, P., Shin, D., Young, K., 2001. Trade-off analysis for marine protected area management. Ecological Economics 37, 417-434.

Carter, D.W., 2003. Protected areas in marine resource management: another look at the economics and research issues. Ocean \& Coastal Management 46, 439-456.

Castilla, J.C., 2000. Roles of experimental marine ecology in coastal management and conservation. Journal of Experimental Marine Biology and Ecology 250, 3-21.

Charbonnel, E., Francour, P., Harmelin, J.-G., Ody, D., Bachet, F., 2000. Effects of artificial reef design on associated fish assemblages in the Côte Bleue Marine Park (Mediterranean Sea, France). In Artificial Reefs in European Seas, eds. A.C. Jensen, K.J. Collins, A.P.M. Lockwood, pp. 365-378. Kluwer Academics Publishers, Dordrecht, The Netherlands.

Charbonnel, E., Serre, C., Ruitton, S., Harmelin, J.-G., Jensen, A., 2002. Effects of increase habitat complexity on fish assemblages associated with large artificial reef units (French Mediterranean coast). ICES Journal of Marine Science 59, S208-S213.

Chee, Y.E., 2004. An ecological perspective on the valuation of ecosystem services. Biological Conservation $120,548-565$.

Chiappone, M., Sealey, K.M.S., 2000. Marine reserve design criteria and measures of success: lessons learned from the Exuma Cays Land and Sea Park, Bahamas. Bulletin of Marine Science 66, 691-705. 
Ciriaco, S., Costantini, M., Italiano, C., Odorico, R., Picciulin, M., Verginella, L., Spoto, M., 1998. Monitoring the Miramare Marine Reserve: assessment of protection efficiency. Italian Journal of Zoology 65, 383-386.

Clarke, K.R., 1993. Non-parametric multivariate analyses of changes in community structure. Australian Journal of Ecology 18, 117-143.

Claudet, J., Pelletier, D., 2004. Marine protected areas and artificial reefs: A review of the interactions between management and scientific studies. Aquatic Living Resources 17, 129-138.

Côté, I.M., Mosqueira, I., Reynolds, J.D., 2001. Effects of marine reserve characteristics on the protection of fish populations: a meta-analysis. Journal of Fish Biology 59, 178-189.

Dahl, A.L., 2000. Using indicators to measure sustainability: recent methodological and conceptual developments. Marine and Freshwater Research 51, 427-433.

De'ath, G., 2002. Multivariate regression trees: a new technique for modeling species-environment relationships. Ecology 83, 1105-1117.

Denny, C.M., Babcock, R.C., 2004. Do partial marine reserves protect reef fish assemblages? Biological Conservation 116, 119-129.

Dufour, V., Jouvenel, J.-Y., Galzin, R., 1995. Study of a Mediterranean reef fish assemblage. Comparisons of population distributions between depths in protected and unprotected areas over one decade. Aquatic Living Resources 8, 17-25.

Dufrêne, M., Legendre, P., 1997. Species assemblages and indicator species: the need for a flexible asymmetrical approach. Ecological Monographs 67, 345-366.

Dugan, J.E., Davis, G.E., 1993. Application of marine refugia to coastal fisheries management. Canadian Journal of Fisheries and Aquatic Sciences 50, 2029-2041.

Edgar, G.J., Barrett, N.S., Morton, A.J., 2004a. Biases associated with the use of underwater visual census techniques to quantify the density and size-structure of fish populations. Journal of Experimental Marine Biology and Ecology 308, 269-290.

Edgar, G.J., Bustamante, R.H., Fariña, J.-M., Calvopiña, M., Martínez, C., Toral-Granda, M.V., 2004b. Bias in evaluating the effects of marine protected areas: the importance of baseline data for the Galapagos Marine Reserve. Environmental Conservation 31, 212-218. 
Fazey, I., Fischer, J., Lindenmayer, D., 2005. What do conservation biologists publish? Biological Conservation 124, 63-73.

Ferraris, J., Pelletier, D., Kulbicki, M., Chauvet, C., 2005. Assessing the impact of removing status on the Abore Reef fish assemblage in New Caledonia. Marine Ecology Progress Series 292, 271286.

Francour, P., 1994. Pluriannual analysis of the reserve effect on ichtyofauna in the Scandola natural reserve (Corsica, Northwestern Mediterranean). Oceanologica Acta 17, 309-317.

Francour, P., Harmelin, J.-G., Pollard, D., Sartoretto, S., 2001. A review of marine protected areas in the northwestern Mediterranean region: siting, usage, zonation and management. Aquatic Conservation: Marine and Freshwater Ecosystems 11, 155-188.

Fraschetti, S., Terlizzi, A., Bussotti, S., Guarnieri, G., D'Ambrosio, P., Boero, F., 2005. Conservation of Mediterranean seascapes: analyses of existing protection schemes. Marine Environmental Research 59, 309-332.

Fraschetti, S., Terlizzi, A., Micheli, F., Benedetti-Cecchi, L., Boero, F., 2002. Marine protected areas in the Mediterranean: objectives, effectiveness and monitoring. Marine Ecology 23, 190-200.

García-Charton, J.A., Pérez-Ruzafa, Á., 1999. Ecological heterogeneity and the evaluation of the effects of marine reserves. Fisheries Research 42, 1-20.

García-Charton, J.A., Williams, I.D., Pérez-Ruzafa, Á., Milazzo, M., Chemello, R., Marcos, C., Kitsos, M.-S., Koukouras, A., Riggio, S., 2000. Evaluating the ecological effects of Mediterranean marine protected areas: habitat, scale and the natural variability of ecosystems. Environmental Conservation 27, 159-178.

Glasby, T.M., 1997. Analysing data from post-impact studies using asymmetrical analysis of variance: A case study of epibiota on marinas. Australian Journal of Ecology 22, 448-459.

Halpern, B., 2003. The impact of marine reserves: do reserves work and does reserve size matter? Ecological Applications 13, S117-S137.

Halpern, B.S., Warner, R.R., 2002. Marine reserves have rapid and lasting effects. Ecology Letters 5, 361-366. 
Harmelin, J.-G., 1999. Visual assessment of indicator fish species in Mediterranean marine protected areas. Naturalista Siciliano 23, 83-104.

Harmelin, J.-G., 2000. Mediterranean marine protected areas: some prominent traits and promising trends. Environmental Conservation 27, 104-105.

Harmelin, J.-G., Bachet, F., Garcia, F., 1995. Mediterranean marine reserves: fish indices as tests of protection efficiency. Marine Ecology 16, 233-250.

Hilborn, R., Stokes, K., Maguire, J.-J., Smith, T., Botsford, L.W., Mangel, M., Orensanz, J., Parma, A., Rice, J., Bell, J.D., Cochrane, K.L., Garcia, S., Hall, S.J., Kirkwood, G.P., Sainsbury, K., Stefansson, G., Walters, C., 2004. When can marine reserve improve fisheries management? Ocean \& Coastal Management 47, 197-205.

Jameson, S.C., Tupper, M.H., Ridley, J.M., 2002. The three screen doors: Can marine "protected" areas be effective? Marine Pollution Bulletin 44, 1177-1183.

Johnson, C.R., Field, C.A., 1993. Using fixed-effects model multivariate analysis of variance in marine biology and ecology. Oceanography and Marine Biology: An Annual Review 31, 177221.

Jouvenel, J.-Y., Pollard, D.A., 2001. Some effects of marine reserve protection on the population structure of two spearfishing target-fish species, Dicentrarchus labrax (Moronidae) and Sparus aurata (Sparidae), in shallow inshore waters, along a rocky coast in the northern Mediterranean Sea. Aquatic Conservation: Marine and Freshwater Ecosystems 11, 1-9.

Kremen, C., 1992. Assessing the indicator proprieties of species assemblage for natural areas monitoring. Ecological Applications 2, 203-217.

Kritzer, J., Davies, C., 2005. Demographic variation within spatially structured reef fish populations: when are larger-bodied subpopulations more important? Ecological Modelling 182, 49-65.

Kulbicki, M., 1998. How the acquired behaviour of commercial reef fishes may influence the results obtained from visual censuses. Journal of Experimental Marine Biology and Ecology 222, 1130.

Lauck, T., Clark, C.W., Mangel, M., Munro, G.R., 1998. Implementing the precautionary principle in fisheries management through marine reserves. Ecological Applications 8, S72-S78. 
Linton, D.M., Warner, G.F., 2003. Biological indicators in the Caribbean coastal zone and their role in integrated coastal management. Ocean \& Coastal Management 46, 261-276.

McArdle, B.H., Anderson, M.J., 2001. Fitting multivariate models to community data: a comment on distance-based redundancy analysis. Ecology 82, 290-297.

McClanahan, T.R., Muthiga, N.A., Kamukuru, A.T., Machano, H., Kiambo, R.W., 1999. The effects of marine parks and fishing on coral reefs of northern Tanzania. Biological Conservation 89, $161-182$.

Mosqueira, I., Côté, I.M., Jennings, S., Reynolds, J., 2000. Conservation benefits of marine reserves for fish populations. Animal Conservation 4, 321-332.

Mouillot, D., Culioli, J.-M., Do Chi, T., 2002. Indicator species analysis as a test of non-random distribution of species in the context of marine protected areas. Environmental Conservation 29, 385-390.

Murray, S.N., Ambrose, R.F., Bohnsack, J.A., Botsford, L.W., Carr, M.H., Davis, G.E., Dayton, P.K., Gotshall, D., Gunderson, D.R., Hixon, M.A., Lubchenco, J., Mangel, M., MacCall, A., McArdle, D.A., 1999. No-take reserve networks: sustaining fishery populations and marine ecosystems. Fisheries 24, 11-25.

Nicholson, M., Fryer, R., 2002. Developing effective environmental indicators--does a new dog need old tricks? Marine Pollution Bulletin 45, 53-61.

Nowlis, J.S., Roberts, C.M., 1999. Fisheries benefits and optimal design of marine reserves. Fishery Bulletin 97, 604-616.

Olsen, S.B., 2003. Frameworks and indicators for assessing progress in integrated coastal management initiatives. Ocean \& Coastal Management 46, 347-361.

Pauly, D., Christensen, V., Guénette, S., Pitcher, T.J., Sumaila, U.R., Walters, C.J., Watson, R., Zeller, D., 2002. Towards sustainability in world fisheries. Nature 418, 689-695.

Pelletier, D., García-Charton, J.A., Ferraris, J., David, G., Thébaud, O., Letourneur, Y., Claudet, J., Amand, M., Kulbicki, M., Galzin, R., 2005. Designing indicators for assessing the effects of marine protected areas on coral reef ecosystems: A multidisciplinary standpoint. Aquatic Living Resources 18, 15-33. 
Pinnegar, J.K., Polunin, N.V.C., Francour, P., Badalamenti, F., Chemello, R., Harmelin-Vivien, M., Hereu, B., Milazzo, M., Zabala, M., D'Anna, G., Pipitone, C., 2000. Trophic cascades in benthic marine ecosystems: lessons for fisheries and protected-area management. Environmental Conservation 27, 179-200.

Pullin, A.S., Knight, T.M., Stone, D.A., Charman, K., 2004. Do conservation managers use scientific evidence to support their decision-making? Biological Conservation 119, 245-252.

Rakitin, A., Kramer, D.L., 1996. Effect of a marine reserve on the distribution of coral reef fishes in Barbados. Marine Ecology Progress Series 131, 97-113.

Roberts, C.M., Polunin, N.V.C., 1991. Are marine reserves effective in management of reef fisheries? Reviews in Fish Biology and Fisheries 1, 65-91.

Rowley, R.J., 1994. Case studies and reviews - Marine reserves in fisheries management. Aquatic Conservation: Marine and Freshwater Ecosystems 4, 233-254.

Rudd, M.A., Tupper, M.H., Folmer, H., van Kooten, G.C., 2003. Policy analysis for tropical marine reserves: challenges and directions. Fish and Fisheries 4, 65-85.

Russ, G.R., 1985. Effects of protective management on coral reef fishes in the central Philippines. In Proceedings of the Fifth International Coral Reef Congress, pp. 219-224, Tahiti.

Russ, G.R., 2002. Yet another review of marine reserve as reef fishery management tools. In Coral reef fishes: dynamics and diversity in a complex ecosystem, ed. P.F. Sale, pp. 421-443. Academic Press, San Diego.

Russ, G.R., Alcala, A.C., 1996. Marine reserves: rates and patterns of recovery and decline of large predatory fish. Ecological Applications 6, 947-961.

Saetersdal, M., Gjerde, I., Blom, H., 2005. Indicator species and the problem of spatial inconsistency in nestedness patterns. Biological Conservation 122, 305-316.

Sainsbury, K., Sumaila, U.R., 2003. Incorporating ecosystem objectives into management of sustainable marine fisheries, including "best practice" reference points and use of marine protected areas. In Responsible Fisheries in the Marine Ecosystem, eds. M. Sinclair, G. Valdimarsson, pp. 343-361. FAO. 
Sale, P., Cowen, R., Danilowicz, B., Jones, G., Kritzer, J., Lindeman, K., Planes, S., Polunin, N., Russ, G., Sadovy, Y., Steneck, R., 2005. Critical science gaps impede use of no-take fishery reserves. Trends in Ecology \& Evolution 20, 74-80.

Sosa-López, A., Mouillot, D., Do Chi, T., Ramos-Miranda, J., 2005. Ecological indicators based on fish biomass distribution along trophic levels: an application to the Terminos coastal lagoon, Mexico. ICES Journal of Marine Science 62, 453-458.

Sumaila, U.R., Guénette, S., Alder, J., Chuenpagdee, R., 2000. Addressing ecosystem effects of fishing using marine protected areas. ICES Journal of Marine Science 57, 752-760.

Therneau, T.M., Atkinson, B., Ripley, B., Oksanen, J., De'ath, G., 2004. The mvpart Package. in G. De'ath, editor. Multivariate partitioning.

Underwood, A.J., 1981. Techniques of analysis of variance in experimental marine biology and ecology. Oceanography and Marine Biology: An Annual Review 19, 513-605.

Underwood, A.J., 1993. The mechanics of spatially replicated sampling programmes to detect environmental impacts in a variable world. Australian Journal of Ecology 18, 99-116.

Underwood, A.J., Chapman, M.G., 1998. A method for analysing spatial scales variation in composition of assemblages. Oecologia 117, 570-578.

Underwood A.J., Chapman M.G., 2003. Power, precaution, Type II error and sampling design in assessment of environmental impacts. Journal of Experimental Marine Biology and Ecology 296, 49-70.

Westera, M., Lavery, P., Hyndes, G., 2003. Differences in recreationally targeted fishes between protected and fished areas of a coral reef marine park. Journal of Experimental Marine Biology and Ecology 294, 145-168.

Willis, T.J., Anderson, M.J., 2003. Structure of cryptic reef fish assemblages: relationships with habitat characteristics and predator density. Marine Ecology Progress Series 257, 209-221.

Willis, T.J., Millar, R.B., Babcock, R.C., Tolimieri, N., 2003. Burdens evidence and the benefits of marine reserves: putting Descartes before des horse? Environmental Conservation 30, 97-103. 
Appendix 1

List of the 40 fish species recorded in the surveys with corresponding frequencies (in \%) across the 3 years, for each site $(n=$ 36 transects) and for each location ( $n=72$ for outside reserve (OR) and $n=108$ for within reserve (WR)), and their class for each group analysed.

\begin{tabular}{|c|c|c|c|c|c|c|c|c|c|c|c|}
\hline \multirow{2}{*}{ Family } & \multirow{2}{*}{ Species } & \multicolumn{5}{|c|}{ Site } & \multicolumn{2}{|c|}{ Location } & \multirow{2}{*}{ Size } & \multirow{2}{*}{ Fishing value } & \multirow{2}{*}{ Mobility } \\
\hline & & OR1 & OR2 & WR1 & WR2 & WR3 & OR & WR & & & \\
\hline Apogonidae & Apogon imberbis & 2.8 & 16.7 & 2.8 & 2.8 & 0 & 9.7 & 1.9 & 1 & $\mathrm{U}$ & $\mathrm{M}$ \\
\hline Centracanthidae & Spicara maena & 2.6 & 19.4 & 2.8 & 16.7 & 16.7 & 25 & 12 & 2 & $\mathrm{U}$ & M \\
\hline Centracanthidae & Spicara smaris & 5.6 & 2.8 & 2.8 & 0 & 11.1 & 4.2 & 4.6 & 1 & $\mathrm{U}$ & M \\
\hline Congridae & Conger conger & 0 & 5.6 & 0 & 0 & 0 & 2.8 & 0 & 3 & $\mathrm{~L}$ & $\mathrm{~S}$ \\
\hline Labridae & Coris julis & 100 & 83.3 & 100 & 100 & 91.7 & 91.7 & 97.2 & 2 & $\mathrm{MH}$ & $\mathrm{S}$ \\
\hline Labridae & Ctenolabrus rupestris & 47.2 & 38.9 & 55.6 & 75 & 83.3 & 43.1 & 71.3 & 1 & L & $\mathrm{S}$ \\
\hline Labridae & Labrus bimaculatus & 5.6 & 0 & 2.8 & 19.4 & 22.2 & 2.8 & 14.8 & 3 & $\mathrm{MH}$ & $\mathrm{S}$ \\
\hline Labridae & Labrus merula & 16.7 & 22.2 & 11.1 & 33.3 & 19.4 & 19.4 & 21.3 & 3 & $\mathrm{MH}$ & $\mathrm{S}$ \\
\hline Labridae & Labrus viridis & 11.1 & 11.1 & 5.6 & 8.3 & 8.3 & 11.1 & 7.4 & 3 & MH & $\mathrm{S}$ \\
\hline Labridae & Symphodus cinereus & 0 & 5.6 & 0 & 0 & 0 & 2.8 & 0 & 1 & $\mathrm{MH}$ & $\mathrm{S}$ \\
\hline Labridae & Symphodus doderleini & 77.8 & 52.8 & 80.6 & 72.2 & 47.2 & 65.3 & 66.7 & 1 & $\mathrm{~L}$ & S \\
\hline Labridae & Symphodus mediterraneus & 61.1 & 41.7 & 63.9 & 77.8 & 72.2 & 51.4 & 71.3 & 1 & $\mathrm{~L}$ & $\mathrm{~S}$ \\
\hline Labridae & Symphodus melanocercus & 52.8 & 50 & 77.8 & 72.2 & 69.4 & 51.4 & 73.1 & 1 & $\mathrm{~L}$ & $\mathrm{~S}$ \\
\hline Labridae & Symphodus ocellatus & 2.6 & 22.2 & 33.3 & 19.4 & 2.8 & 26.4 & 18.5 & 1 & $\mathrm{~L}$ & $\mathrm{~S}$ \\
\hline Labridae & Symphodus roissali & 25 & 33.3 & 27.8 & 16.7 & 0 & 29.2 & 14.8 & 1 & $\mathrm{~L}$ & $\mathrm{~S}$ \\
\hline Labridae & Symphodus rostratus & 2.6 & 36.1 & 36.1 & 2.6 & 13.9 & 33.3 & 26.9 & 1 & $\mathrm{~L}$ & $\mathrm{~S}$ \\
\hline Labridae & Symphodus tinca & 38.9 & 2.6 & 47.2 & 41.7 & 19.4 & 34.7 & 36.1 & 2 & $\mathrm{MH}$ & $\mathrm{S}$ \\
\hline Moronidae & Dicentrarchus labrax & 0 & 0 & 5.6 & 0 & 0 & 0 & 1.9 & 3 & MH & M \\
\hline Mugilidae & Chelon labrosus & 0 & 0 & 2.8 & 0 & 0 & 0 & 0.9 & 3 & $\mathrm{~L}$ & M \\
\hline Mullidae & Mullus surmuletus & 27.8 & 19.4 & 44.4 & 27.8 & 2.6 & 23.6 & 34.3 & 2 & MH & M \\
\hline Muraenidae & Muraena helena & 0 & 5.6 & 0 & 0 & 0 & 2.8 & 0 & 3 & $\mathrm{~L}$ & $\mathrm{~S}$ \\
\hline Pomacentridae & Chromis chromis & 86.1 & 77.8 & 86.1 & 83.3 & 94.4 & 81.9 & 88 & 1 & $\mathrm{U}$ & $\mathrm{M}$ \\
\hline Scorpaenidae & Scorpaena notata & 0 & 0 & 2.8 & 2.8 & 8.3 & 0 & 4.6 & 1 & $\mathrm{MH}$ & $\mathrm{S}$ \\
\hline Scorpaenidae & Scorpaena porcus & 0 & 5.6 & 0 & 8.3 & 27.8 & 2.8 & 12 & 2 & $\mathrm{MH}$ & $\mathrm{S}$ \\
\hline Scorpaenidae & Scorpaena scrofa & 2.8 & 0 & 0 & 2.8 & 11.1 & 1.4 & 4.6 & 3 & MH & $\mathrm{S}$ \\
\hline Serranidae & Anthias anthias & 0 & 0 & 0 & 0 & 5.6 & 0 & 1.9 & 1 & $\mathrm{U}$ & M \\
\hline Serranidae & Epinephelus caninus & 0 & 0 & 0 & 0 & 2.8 & 0 & 0.9 & 3 & MH & $\mathrm{S}$ \\
\hline Serranidae & Epinephelus marginatus & 0 & 0 & 0 & 0 & 5.6 & 0 & 1.9 & 3 & $\mathrm{MH}$ & $\mathrm{S}$ \\
\hline Serranidae & Serranus cabrilla & 97.2 & 61.1 & 94.4 & 97.2 & 75 & 79.2 & 88.9 & 2 & $\mathrm{MH}$ & $\mathrm{S}$ \\
\hline Serranidae & Serranus scriba & 13.9 & 11.1 & 2.8 & 2.8 & 0 & 12.5 & 1.9 & 2 & $\mathrm{MH}$ & $\mathrm{S}$ \\
\hline Sparidae & Boops boops & 47.2 & 11.1 & 11.1 & 16.7 & 33.3 & 29.2 & 1.4 & 2 & $\mathrm{~L}$ & M \\
\hline Sparidae & Dentex dentex & 0 & 0 & 2.8 & 0 & 2.8 & 0 & 1.9 & 3 & $\mathrm{MH}$ & $M$ \\
\hline Sparidae & Diplodus annularis & 2.8 & 8.3 & 2.8 & 5.6 & 0 & 5.6 & 2.8 & 1 & MH & M \\
\hline Sparidae & Diplodus sargus & 22.2 & 16.7 & 36.1 & 58.3 & 44.4 & 19.4 & 46.3 & 2 & $\mathrm{MH}$ & M \\
\hline Sparidae & Diplodus vulgaris & 16.7 & 38.9 & 33.3 & 41.7 & 52.8 & 27.8 & 42.6 & 2 & $\mathrm{MH}$ & M \\
\hline Sparidae & Oblada melanura & 0 & 0 & 2.8 & 0 & 0 & 0 & 0.9 & 1 & $\mathrm{~L}$ & M \\
\hline Sparidae & Pagellus erythrynus & 0 & 0 & 0 & 0 & 2.8 & 0 & 0.9 & 3 & MH & M \\
\hline Sparidae & Sarpa salpa & 5.6 & 13.9 & 19.4 & 5.6 & 8.3 & 9.7 & 11.1 & 3 & $\mathrm{~L}$ & M \\
\hline Sparidae & Sparus pagurus & 2.8 & 0 & 2.8 & 2.8 & 2.8 & 1.4 & 2.8 & 3 & MH & M \\
\hline Sparidae & Spondyliosoma cantharus & 0 & 2.8 & 2.8 & 0 & 2.8 & 1.4 & 1.9 & 3 & MH & $\mathrm{M}$ \\
\hline
\end{tabular}

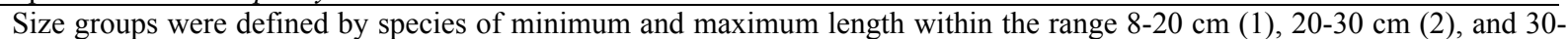
$200 \mathrm{~cm}$ (3). Fishing value groups corresponded to unfished species (U) and species with low (L) or medium to high (MH) fishing value. Mobility groups were defined by sedentary (S) or mobile (M) species. 
Appendix 2

Mean species abundances per site and per year $( \pm \mathrm{SE})$.

\begin{tabular}{|c|c|c|c|c|c|c|}
\hline \multirow{2}{*}{$\begin{array}{l}\text { Group/species } \\
\text { considered }\end{array}$} & \multicolumn{2}{|c|}{1995} & \multicolumn{2}{|c|}{1998} & \multicolumn{2}{|r|}{2001} \\
\hline & WR & OR & WR & OR & WR & OR \\
\hline \multicolumn{7}{|l|}{ FISH SIZES } \\
\hline All & $3.24 \pm 0.73$ & $2.58 \pm 0.49$ & $2.88 \pm 0.61$ & $2.46 \pm 0.62$ & $6.3 \pm 3.1$ & $2.32 \pm 0.58$ \\
\hline Large & $1.22 \pm 0.58$ & $0.65 \pm 0.24$ & $0.74 \pm 0.17$ & $0.45 \pm 0.23$ & $0.56 \pm 0.08$ & $0.56 \pm 0.32$ \\
\hline Medium & $1.8 \pm 0.43$ & $1.25 \pm 0.32$ & $1.8 \pm 0.55$ & $1.89 \pm 0.56$ & $5.51 \pm 3.1$ & $1.68 \pm 0.44$ \\
\hline Small & $0.21 \pm 0.06$ & $0.68 \pm 0.25$ & $0.34 \pm 0.1$ & $0.11 \pm 0.03$ & $0.22 \pm 0.05$ & $0.08 \pm 0.02$ \\
\hline \multicolumn{7}{|l|}{ SPECIES SIZES } \\
\hline Large & $0.01 \pm 0.01$ & $0.02 \pm 0.01$ & $0.15 \pm 0.08$ & $0.08 \pm 0.02$ & $0.27 \pm 0.13$ & $0.02 \pm 0.01$ \\
\hline Medium & $2.66 \pm 0.39$ & $2.81 \pm 0.55$ & $2.64 \pm 0.41$ & $3.02 \pm 0.44$ & $4.71 \pm 0.67$ & $3.68 \pm 0.97$ \\
\hline Small & $7.28 \pm 2.01$ & $5.31 \pm 1.3$ & $6.15 \pm 1.68$ & $4.77 \pm 1.71$ & $14.21 \pm 8.67$ & $4.03 \pm 1.48$ \\
\hline \multicolumn{7}{|l|}{ FISHING VALUE } \\
\hline Unfished & $20.23 \pm 5.86$ & $14.35 \pm 14.35$ & $17.16 \pm 4.91$ & $14.77 \pm 5.06$ & $41.35 \pm 25.9$ & $12.49 \pm 4.38$ \\
\hline Low & $0.78 \pm 0.1$ & $0.98 \pm 0.33$ & $0.63 \pm 0.11$ & $0.65 \pm 0.11$ & $1.07 \pm 0.25$ & $1.36 \pm 0.68$ \\
\hline Medium to high & $1.03 \pm 0.16$ & $0.99 \pm 0.16$ & $1.13 \pm 0.18$ & $0.87 \pm 0.15$ & $1.84 \pm 0.28$ & $0.73 \pm 0.73$ \\
\hline \multicolumn{7}{|l|}{ SPECIES MOBILITY } \\
\hline Mobile species & $5.58 \pm 1.59$ & $4.13 \pm 1.05$ & $4.78 \pm 1.34$ & $4.17 \pm 1.36$ & $11.58 \pm 6.85$ & $4.09 \pm 1.26$ \\
\hline Sedentary species & $1.3 \pm 0.17$ & $1.29 \pm 0.17$ & $1.31 \pm 0.18$ & $1.04 \pm 0.15$ & $1.94 \pm 0.28$ & $0.86 \pm 0.16$ \\
\hline \multicolumn{7}{|l|}{ COMMUNITY } \\
\hline \multicolumn{7}{|l|}{ METRICS } \\
\hline Total fish abundance & $135.92 \pm 23.40$ & $108.21 \pm 14.12$ & $121.10 \pm 18.89$ & $103.12 \pm 22.54$ & $264.71 \pm 127.56$ & $97.58 \pm 23.97$ \\
\hline Total fish abundance (L) & $51.33 \pm 23.41$ & $27.17 \pm 9.73$ & $31.12 \pm 6.77$ & $18.80 \pm 9.94$ & $23.71 \pm 3.27$ & $23.71 \pm 13.48$ \\
\hline Species richness & $8.71 \pm 0.57$ & $9.92 \pm 0.51$ & $9.10 \pm 0.43$ & $9.04 \pm 0.53$ & $9.87 \pm 0.60$ & $5.12 \pm 0.78$ \\
\hline Species richness (L) & $5.21 \pm 0.44$ & $5.83 \pm 0.47$ & $6.87 \pm 0.47$ & $4.04 \pm 0.55$ & $6.5 \pm 0.61$ & $2.46 \pm 0.37$ \\
\hline Diversity & $1.53 \pm 0.13$ & $1.70 \pm 0.11$ & $1.63 \pm 0.12$ & $1.78 \pm 0.12$ & $1.82 \pm 0.14$ & $1.05 \pm 0.16$ \\
\hline Diversity(L) & $1.65 \pm 0.17$ & $1.86 \pm 0.18$ & $2.12 \pm 0.13$ & $1.40 \pm 0.17$ & $1.91 \pm 0.13$ & $0.83 \pm 0.14$ \\
\hline \multicolumn{7}{|l|}{ FISH SPECIES } \\
\hline Coris julis & $18.00 \pm 1.35$ & $18.00 \pm 1.25$ & $19.6 \pm 1.52$ & $16.70 \pm 1.21$ & $31.67 \pm 1.65$ & $14.33 \pm 2.25$ \\
\hline Coris julis (L) & $2.92 \pm 0.33$ & $2.46 \pm 0.29$ & $5.37 \pm 0.41$ & $1.62 \pm 0.33$ & $9.10 \pm 0.61$ & $2.54 \pm 0.54$ \\
\hline Serranus cabrilla & $2.17 \pm 0.21$ & $2.29 \pm 0.28$ & $3.12 \pm 0.30$ & $1.08 \pm 0.18$ & $3.71 \pm 0.34$ & $2.21 \pm 0.50$ \\
\hline Serranus cabrilla $(\mathrm{L})$ & $0.33 \pm 0.11$ & $0.62 \pm 0.18$ & $2.46 \pm 0.24$ & $0.29 \pm 0.13$ & $1.54 \pm 0.24$ & $0.17 \pm 0.10$ \\
\hline Symphodus doderleini & $1.58 \pm 0.21$ & $1.92 \pm 0.20$ & $1.75 \pm 0.23$ & $0.75 \pm 0.23$ & $1.83 \pm 0.37$ & $1.04 \pm 0.26$ \\
\hline Symphodus doderleini (L) & $0.96 \pm 0.16$ & $1.17 \pm 0.18$ & $1.37 \pm 0.21$ & $0.75 \pm 0.16$ & $0.67 \pm 0.18$ & $0.50 \pm 0.13$ \\
\hline
\end{tabular}

Site WR3 removed from WR location. Species with null abundance in a group were kept in the mean and standard error computations. (L) means large fish. 
Table 1

PERMANOVA table of abundances per fish species conducted on fish size group.

\begin{tabular}{|c|c|c|c|c|c|c|}
\hline Fish considered & Source of variation & $d f$ & SS & $F$ & $P$ & \\
\hline All & Year & 2 & 45.29 & 5.65 & 0.0002 & *** \\
\hline \multirow[t]{5}{*}{ (40 variables) } & Location & 1 & 47.37 & 11.82 & 0.0002 & $* * *$ \\
\hline & Site(Location) & 2 & 35.68 & 4.45 & 0.0002 & $* * *$ \\
\hline & $\mathrm{Ye} \times \mathrm{Lo}$ & 2 & 56.06 & 6.99 & 0.0002 & $* * *$ \\
\hline & $\mathrm{Ye} \times \mathrm{Si}(\mathrm{Lo})$ & 4 & 33.15 & 2.07 & 0.0130 & * \\
\hline & Residual & 132 & 528.95 & & & \\
\hline Large & $\mathrm{Ye}$ & 2 & 21.69 & 6.04 & 0.0004 & *** \\
\hline \multirow[t]{5}{*}{ (40 variables) } & Lo & 1 & 2.54 & 17.02 & 0.0002 & $* * *$ \\
\hline & $\mathrm{Si}(\mathrm{Lo})$ & 2 & 7.54 & 2.10 & 0.0718 & n.s. \\
\hline & $\mathrm{Ye} \times \mathrm{Lo}$ & 2 & 1.88 & 5.82 & 0.0004 & $* * *$ \\
\hline & $\mathrm{Ye} \times \operatorname{Si}(\mathrm{Lo})$ & 4 & 8.34 & 1.16 & 0.3272 & n.s. \\
\hline & Residual & 132 & 236.81 & & & \\
\hline Medium & $\mathrm{Ye}$ & 2 & 25.39 & 4.66 & 0.0012 & $* *$ \\
\hline \multirow[t]{5}{*}{ (40 variables) } & Lo & 1 & 19.36 & 7.10 & 0.0002 & $* * *$ \\
\hline & $\mathrm{Si}(\mathrm{Lo})$ & 2 & 21.56 & 3.96 & 0.0030 & $* *$ \\
\hline & $\mathrm{Ye} \times \mathrm{Lo}$ & 2 & 29.39 & 5.39 & 0.0002 & $* * *$ \\
\hline & $\mathrm{Ye} \times \operatorname{Si}(\mathrm{Lo})$ & 4 & 16.78 & 1.54 & 0.1316 & n.s. \\
\hline & Residual & 132 & 359.74 & & & \\
\hline Small & $\mathrm{Ye}$ & 2 & 5.92 & 3.72 & 0.0038 & $* *$ \\
\hline \multirow[t]{5}{*}{ (40 variables) } & Lo & 1 & 1.06 & 1.33 & 0.2886 & n.s. \\
\hline & $\mathrm{Si}(\mathrm{Lo})$ & 2 & 5.61 & 3.52 & 0.0052 & $* *$ \\
\hline & $\mathrm{Ye} \times \mathrm{Lo}$ & 2 & 4.21 & 2.65 & 0.0256 & * \\
\hline & $\mathrm{Ye} \times \operatorname{Si}(\mathrm{Lo})$ & 4 & 6.21 & 1.95 & 0.0438 & * \\
\hline & Residual & 132 & 104.99 & & & \\
\hline
\end{tabular}

PERMANOVAs were based on the binomial deviance dissimilarity measure. $P$-values were obtained using 4999 permutations of residuals under a reduced model. $P$-values: $* * *<0.001 ; * *<0.01 ; *<0.05$. 
Table 2

$P$-values for pair-wise comparisons conducted after PERMANOVAs of fish species abundance data. Comparisons were performed for inside/outside differences for each year.

\begin{tabular}{|c|c|c|c|c|c|c|}
\hline \multirow{2}{*}{$\begin{array}{l}\text { Variables } \\
\text { All fish }\end{array}$} & \multicolumn{2}{|c|}{$\begin{array}{l}\text { 1995: WR vs. OR } \\
P\end{array}$} & \multicolumn{2}{|c|}{$\begin{array}{l}\text { 1998: WR vs. OR } \\
P\end{array}$} & \multicolumn{2}{|c|}{$\begin{array}{l}\text { 2001: WR vs. OR } \\
P\end{array}$} \\
\hline & 0.0896 & n.s. & 0.0002 & $* * *$ & 0.0002 & $* * *$ \\
\hline Large fish & 0.4688 & n.s. & 0.0002 & $* * *$ & 0.0002 & $* * *$ \\
\hline Medium fish & 0.2010 & n.s. & 0.0008 & $* * *$ & 0.0004 & $* * *$ \\
\hline Small fish & 0.1176 & n.s. & 0.1910 & n.s. & 0.0786 & n.s. \\
\hline Large species $(30-200 \mathrm{~cm})$ & 0.9998 & n.s. & 0.1776 & n.s. & 0.0046 & $* *$ \\
\hline Medium species $(20-30 \mathrm{~cm})$ & 0.9164 & n.s. & 0.0002 & $* * *$ & 0.0004 & $* * *$ \\
\hline Small species $(8-20 \mathrm{~cm})$ & 0.0376 & $*$ & 0.0198 & * & 0.0016 & $* *$ \\
\hline Low value commercial species & 0.0182 & $*$ & 0.0002 & $* * *$ & 0.0004 & $* * *$ \\
\hline Medium to high value commercial species & 0.6396 & n.s. & 0.0032 & $* *$ & 0.0002 & $* * *$ \\
\hline Mobile species & 0.8100 & n.s. & 0.0004 & $* * *$ & 0.0004 & $* * *$ \\
\hline Sedentary species & 0.0200 & $*$ & 0.0002 & $* * *$ & 0.0002 & $* * *$ \\
\hline
\end{tabular}

Only the metrics for which the interaction (Year $\times$ Location) was significant are reported (see Table 1, Table 3, Table 4 and Table 5). WR: Within Reserve; OR: Outside Reserve. $P$-values were obtained using 4999 permutations. The pair-wise tests have not been corrected for multiple comparisons. $P$-values: $* * *<0.001 ; * *<0.01 ; *<0.05$. 
Table 3

PERMANOVA table of abundance per species when analyses were conducted per species size group.

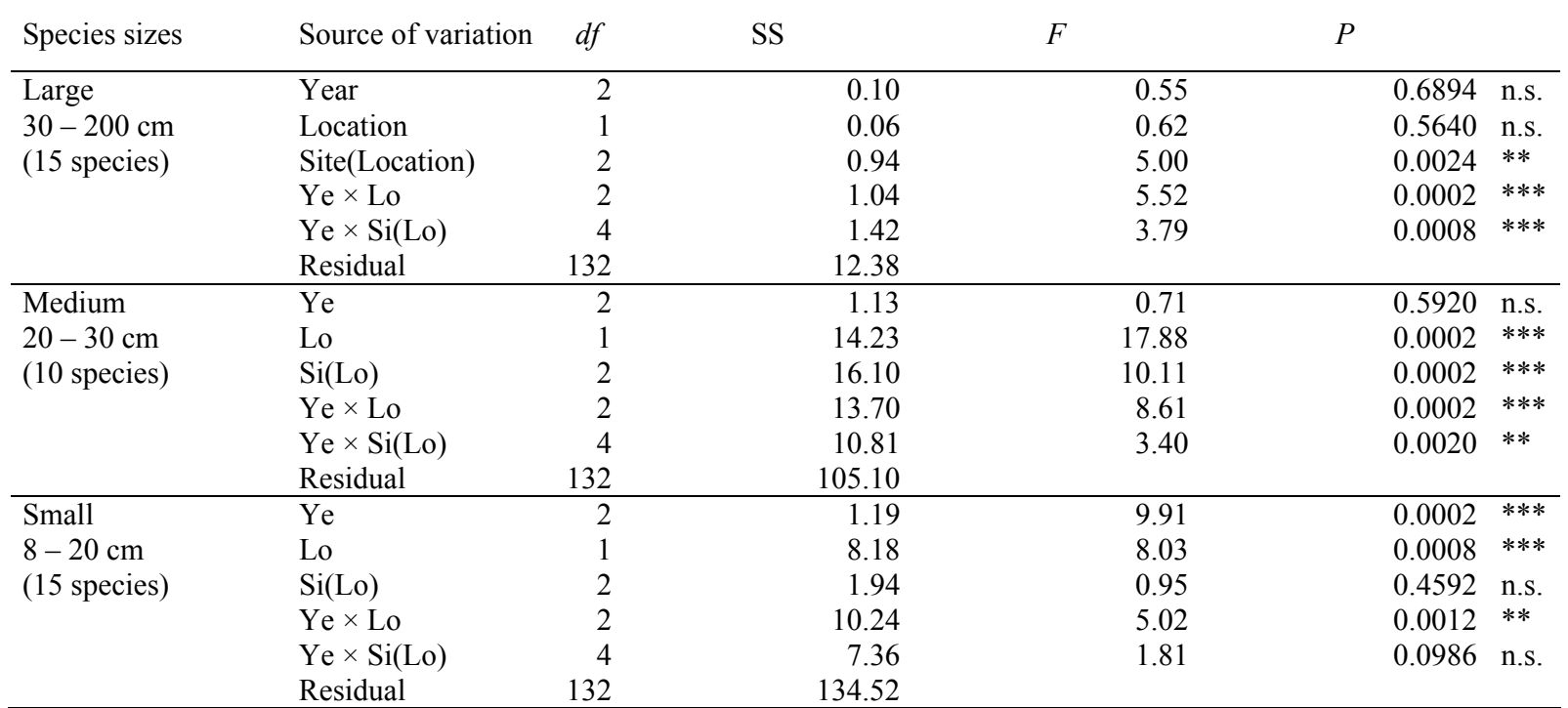

PERMANOVAs were based on the binomial deviance dissimilarity measure. $P$-values were obtained using 4999 permutations of residuals under a reduced model. $P$-values: $* * *<0.001 ; * *<0.01 ; *<0.05$. The range of species sizes is reported for each group. 
Table 4

PERMANOVA table of abundance per species when analyses were conducted per species group based on fishing value.

\begin{tabular}{|c|c|c|c|c|c|c|}
\hline Fishing value & Source of variation & $d f$ & SS & $F$ & & \\
\hline Unfished & Year & 2 & 2.89 & 3.95 & 0.0252 & $*$ \\
\hline \multirow[t]{5}{*}{ (5 species) } & Location & 1 & 0.75 & 2.05 & 0.1824 & n.s. \\
\hline & Site(Location) & 2 & 0.62 & 0.85 & 0.4704 & n.s. \\
\hline & $\mathrm{Ye} \times \mathrm{Lo}$ & 2 & 1.50 & 2.05 & 0.1496 & n.s. \\
\hline & $\mathrm{Ye} \times \operatorname{Si}(\mathrm{Lo})$ & 4 & 2.89 & 1.98 & 0.1174 & n.s. \\
\hline & Residual & 132 & 48.20 & & & \\
\hline Low & $\mathrm{Ye}$ & 2 & 13.45 & 8.55 & 0.0002 & $* * *$ \\
\hline \multirow[t]{5}{*}{ (13 species) } & Lo & 1 & 8.93 & 11.36 & 0.0002 & $* * *$ \\
\hline & $\mathrm{Si}(\mathrm{Lo})$ & 2 & 8.79 & 5.59 & 0.0002 & $* * *$ \\
\hline & $\mathrm{Ye} \times \mathrm{Lo}$ & 2 & 7.44 & 4.73 & 0.0006 & $* * *$ \\
\hline & $\mathrm{Ye} \times \operatorname{Si}(\mathrm{Lo})$ & 4 & 3.64 & 1.16 & 0.3462 & n.s. \\
\hline & Residual & 132 & 103.83 & & & \\
\hline Medium to high & $\mathrm{Ye}$ & 2 & 1.42 & 1.30 & 0.3008 & n.s. \\
\hline \multirow[t]{5}{*}{ (22 species) } & Lo & 1 & 9.95 & 18.18 & 0.0002 & $* * *$ \\
\hline & $\mathrm{Si}(\mathrm{Lo})$ & 2 & 4.99 & 4.56 & 0.0028 & $* *$ \\
\hline & $\mathrm{Ye} \times \mathrm{Lo}$ & 2 & 11.72 & 10.71 & 0.0002 & $* * *$ \\
\hline & $\mathrm{Ye} \times \operatorname{Si}(\mathrm{Lo})$ & 4 & 6.22 & 2.84 & 0.0086 & $* *$ \\
\hline & Residual & 132 & 72.26 & & & \\
\hline
\end{tabular}

PERMANOVAs were based on the binomial deviance dissimilarity measure. $P$-values were obtained using 4999 permutations of residuals under a reduced model. $P$-values: $* * *<0.001 ; * *<0.01 ; *<0.05$. 
Table 5

PERMANOVA table of abundance per species when analyses were conducted per species group based on mobility.

\begin{tabular}{|c|c|c|c|c|c|c|}
\hline Species mobility & Source of variation & $d f$ & SS & $F$ & $P$ & \\
\hline \multirow{6}{*}{$\begin{array}{l}\text { Mobile species } \\
\text { (18 species) }\end{array}$} & Year & 2 & 7.99 & 3.02 & 0.0214 & $*$ \\
\hline & Location & 1 & 11.23 & 8.49 & 0.0002 & $* * *$ \\
\hline & Site(Location) & 2 & 11.69 & 4.42 & 0.0018 & $* *$ \\
\hline & $\mathrm{Ye} \times \mathrm{Lo}$ & 2 & 15.75 & 5.95 & 0.0002 & $* * *$ \\
\hline & $\mathrm{Ye} \times \mathrm{Si}(\mathrm{Lo})$ & 4 & 7.46 & 1.41 & 0.2276 & n.s. \\
\hline & Residual & 132 & 174.55 & & & \\
\hline \multirow{6}{*}{$\begin{array}{l}\text { Sedentary species } \\
\text { (22 species) }\end{array}$} & $\mathrm{Ye}$ & 2 & 16.54 & 8.68 & 0.0002 & $* * *$ \\
\hline & Lo & 1 & 15.19 & 15.93 & 0.0002 & $* * *$ \\
\hline & $\mathrm{Si}(\mathrm{Lo})$ & 2 & 7.34 & 3.85 & 0.0014 & $* *$ \\
\hline & $\mathrm{Ye} \times \mathrm{Lo}$ & 2 & 14.69 & 7.70 & 0.0002 & $* * *$ \\
\hline & $\mathrm{Ye} \times \operatorname{Si}(\mathrm{Lo})$ & 4 & 8.37 & 2.19 & 0.0158 & $*$ \\
\hline & Residual & 132 & 125.85 & & & \\
\hline
\end{tabular}

PERMANOVAs were based on the binomial deviance dissimilarity measure. $P$-values were obtained using 4999 permutations of residuals under a reduced model. $P$-values: $* * *<0.001 ; * *<0.01 ; *<0.05$. 
Table 6

ANOVA table for permutational univariate analyses of total abundance and diversity metrics.

\begin{tabular}{|c|c|c|c|c|c|c|}
\hline Community metrics & Source of variation & $d f$ & SS & $F$ & & \\
\hline Total fish abundance: & & & & & & \\
\hline All fish & Year & 2 & 6.61 & 3.08 & 0.0496 & * \\
\hline & Location & 1 & 12.57 & 11.69 & 0.0008 & $* * *$ \\
\hline & Site(Location) & 2 & 6.25 & 2.91 & 0.0564 & n.s. \\
\hline & $\mathrm{Ye} \times \mathrm{Lo}$ & 2 & 14.15 & 6.58 & 0.0024 & $* *$ \\
\hline & $\mathrm{Ye} \times \mathrm{Si}(\mathrm{Lo})$ & 4 & 27.74 & 6.45 & 0.0006 & $* * *$ \\
\hline & Residual & 132 & 141.94 & & & \\
\hline Large fish & $\mathrm{Ye}$ & 2 & 2.36 & 0.99 & 0.3838 & n.s. \\
\hline & Lo & 1 & 26.21 & 21.94 & 0.0002 & $* * *$ \\
\hline & $\mathrm{Si}(\mathrm{Lo})$ & 2 & 7.12 & 2.99 & 0.0530 & n.s. \\
\hline & $\mathrm{Ye} \times \mathrm{Lo}$ & 2 & 10.51 & 4.41 & 0.0134 & $*$ \\
\hline & $\mathrm{Ye} \times \mathrm{Si}(\mathrm{Lo})$ & 4 & 6.41 & 1.34 & 0.2602 & n.s. \\
\hline & Residual & 132 & 157.68 & & & \\
\hline Species richness: & & & & & & \\
\hline All fish & $\mathrm{Ye}$ & 2 & 92.62 & 6.38 & 0.0030 & ** \\
\hline & Lo & 1 & 51.36 & 7.08 & 0.0092 & ** \\
\hline & $\mathrm{Si}(\mathrm{Lo})$ & 2 & 27.22 & 1.88 & 0.1530 & n.s. \\
\hline & $\mathrm{Ye} \times \mathrm{Lo}$ & 2 & 236.93 & 16.33 & 0.0002 & $* * *$ \\
\hline & $\mathrm{Ye} \times \mathrm{Si}(\mathrm{Lo})$ & 4 & 106.11 & 3.66 & 0.0064 & ** \\
\hline & Residual & 132 & 957.50 & & & \\
\hline Large fish & $\mathrm{Ye}$ & 2 & 32.76 & 2.87 & 0.0624 & n.s. \\
\hline & Lo & 1 & 156.25 & 27.34 & 0.0002 & $* * *$ \\
\hline & $\mathrm{Si}(\mathrm{Lo})$ & 2 & 10.00 & 0.88 & 0.4190 & n.s. \\
\hline & $\mathrm{Ye} \times \mathrm{Lo}$ & 2 & 140.79 & 12.32 & 0.0002 & $* * *$ \\
\hline & $\mathrm{Ye} \times \operatorname{Si}(\mathrm{Lo})$ & 4 & 34.33 & 1.50 & 0.2008 & n.s. \\
\hline & Residual & 132 & 754.50 & & & \\
\hline Diversity: & & & & & & \\
\hline All fish & $\mathrm{Ye}$ & 2 & 1.83 & 2.74 & 0.0674 & n.s. \\
\hline & Lo & 1 & 0.82 & 2.45 & 0.1332 & n.s. \\
\hline & $\mathrm{Si}(\mathrm{Lo})$ & 2 & 8.97 & 13.41 & 0.0002 & $* * *$ \\
\hline & $\mathrm{Ye} \times \mathrm{Lo}$ & 2 & 6.92 & 10.35 & 0.0004 & $* * *$ \\
\hline & $\mathrm{Ye} \times \mathrm{Si}(\mathrm{Lo})$ & 4 & 5.36 & 4.01 & 0.0052 & $* *$ \\
\hline & Residual & 132 & 44.13 & & & \\
\hline Large fish & $\mathrm{Ye}$ & 2 & 4.80 & 4.44 & 0.0136 & $*$ \\
\hline & Lo & 1 & 10.17 & 18.80 & 0.0002 & $* * *$ \\
\hline & $\mathrm{Si}(\mathrm{Lo})$ & 2 & 1.15 & 1.07 & 0.3498 & n.s. \\
\hline & $\mathrm{Ye} \times \mathrm{Lo}$ & 2 & 10.78 & 9.96 & 0.0002 & $* * *$ \\
\hline & $\mathrm{Ye} \times \mathrm{Si}(\mathrm{Lo})$ & 4 & 5.91 & 2.73 & 0.0326 & $*$ \\
\hline & Residual & 132 & 71.40 & & & \\
\hline
\end{tabular}

Permutational univariate ANOVAs were based on Euclidean distances. $P$-values were obtained using 4999 permutations of residuals under a reduced model. $P$-values: $* * *<0.001 ; * *<0.01 ; *<0.05$. 
Table 7

$P$-values for pair-wise comparisons conducted after permutational univariate ANOVAs of total abundance, species and diversity metrics and abundance of two fished species (Coris julis and Serranus cabrilla) and one species with low fishing value (Symphodus doderleini). Comparisons were performed for inside/outside differences for each year.

\begin{tabular}{|c|c|c|c|c|c|c|}
\hline \multirow{2}{*}{$\begin{array}{l}\text { Variables } \\
\text { Number of fish }\end{array}$} & \multicolumn{2}{|c|}{$\begin{array}{l}\text { 1995: WR vs. OR } \\
P \\
\end{array}$} & \multicolumn{2}{|c|}{$\begin{array}{l}\text { 1998: WR vs. OR } \\
P\end{array}$} & \multicolumn{2}{|c|}{$\begin{array}{l}\text { 2001: WR vs. OR } \\
P\end{array}$} \\
\hline & 0.7110 & n.s. & 0.2744 & n.s. & 0.0038 & ** \\
\hline Number of fish (large fish individuals) & 0.7740 & n.s. & 0.0004 & $* * *$ & 0.0002 & $* * *$ \\
\hline Species richness & 0.1344 & n.s. & 1.0000 & n.s. & 0.0002 & $* * *$ \\
\hline Species richness (large fish individuals) & 0.3702 & n.s. & 0.0006 & $* * *$ & 0.0002 & $* * *$ \\
\hline Diversity & 0.3536 & n.s. & 0.3790 & n.s. & 0.0008 & $* * *$ \\
\hline Diversity (large fish individuals) & 0.3796 & n.s. & 0.0012 & $* *$ & 0.0002 & $* * *$ \\
\hline Coris julis (all fish) & 0.9326 & n.s. & 0.1256 & n.s. & 0.0002 & $* * *$ \\
\hline Coris julis (large fish individuals) & 0.2550 & n.s. & 0.0002 & $* * *$ & 0.0002 & $* * *$ \\
\hline Serranus cabrilla (all fish) & 0.9480 & n.s. & 0.0002 & $* * *$ & 0.0028 & $* *$ \\
\hline Serranus cabrilla (large fish individuals) & 0.0736 & n.s. & 0.0002 & $* * *$ & 0.0002 & $* * *$ \\
\hline Symphodus doderleini (all fish) & 0.2160 & n.s. & 0.0024 & $* *$ & 0.1394 & n.s. \\
\hline Symphodus doderleini (large fish individuals) & 0.4532 & n.s. & 0.0022 & $* *$ & 0.6334 & n.s. \\
\hline
\end{tabular}

Only the metrics for which the interaction (Year $\times$ Location) was significant are reported (see Table 6 and Table 8). WR: Within Reserve; OR: Outside Reserve. $P$-values were obtained using 4999 permutations. The pair-wise tests have not been corrected for multiple comparisons. $P$-values: $* * *<0.001 ; * *<0.01 ; *<0.05$. 
Table 8

ANOVA table for permutational univariate analyses of the abundance of two fished species (Coris julis and Serranus cabrilla) and one species with low fishing value (Symphodus doderleini).

\begin{tabular}{|c|c|c|c|c|c|c|}
\hline Fish species & $\begin{array}{l}\text { Source of } \\
\text { variation }\end{array}$ & $d f$ & SS & $F$ & $P$ & \\
\hline \multicolumn{7}{|l|}{ Coris julis: } \\
\hline \multirow[t]{6}{*}{ All fish } & Year & 2 & 0.22 & 0.40 & 0.6730 & n.s. \\
\hline & Location & 1 & 8.37 & 29.86 & 0.0002 & $* * *$ \\
\hline & Site(Location) & 2 & 5.95 & 10.62 & 0.0002 & $* * *$ \\
\hline & $\mathrm{Ye} \times \mathrm{Lo}$ & 2 & 12.02 & 21.46 & 0.0002 & $* * *$ \\
\hline & $\mathrm{Ye} \times \mathrm{Si}(\mathrm{Lo})$ & 4 & 11.62 & 10.37 & 0.0002 & $* * *$ \\
\hline & Residual & 132 & 36.99 & & & \\
\hline \multirow[t]{6}{*}{ Large fish } & $\mathrm{Ye}$ & 2 & 4.56 & 10.47 & 0.0004 & $* * *$ \\
\hline & Lo & 1 & 24.14 & 110.77 & 0.0002 & $* * *$ \\
\hline & $\mathrm{Si}(\mathrm{Lo})$ & 2 & 4.96 & 11.39 & 0.0002 & $* * *$ \\
\hline & $\mathrm{Ye} \times$ Lo & 2 & 8.60 & 19.74 & 0.0002 & $* * *$ \\
\hline & $\mathrm{Ye} \times \mathrm{Si}(\mathrm{Lo})$ & 4 & 1.78 & 2.04 & 0.0880 & n.s. \\
\hline & Residual & 132 & 28.76 & & & \\
\hline \multicolumn{7}{|l|}{ Serranus cabrilla: } \\
\hline \multirow[t]{6}{*}{ All fish } & $\mathrm{Ye}$ & 2 & 1.09 & 2.73 & 0.0710 & n.s. \\
\hline & Lo & 1 & 6.02 & 2.06 & 0.0002 & $* * *$ \\
\hline & $\mathrm{Si}(\mathrm{Lo})$ & 2 & 4.74 & 11.85 & 0.0004 & $* * *$ \\
\hline & $\mathrm{Ye} \times \mathrm{Lo}$ & 2 & 3.33 & 8.32 & 0.0002 & $* * *$ \\
\hline & $\mathrm{Ye} \times \mathrm{Si}(\mathrm{Lo})$ & 4 & 1.15 & 1.44 & 0.2364 & n.s. \\
\hline & Residual & 132 & 26.43 & & & \\
\hline \multirow[t]{6}{*}{ Large fish } & $\mathrm{Ye}$ & 2 & 3.13 & 10.29 & 0.0004 & $* * *$ \\
\hline & Lo & 1 & 9.00 & 59.20 & 0.0002 & $* * *$ \\
\hline & $\mathrm{Si}(\mathrm{Lo})$ & 2 & 0.70 & 2.29 & 0.1058 & n.s. \\
\hline & $\mathrm{Ye} \times \mathrm{Lo}$ & 2 & 9.40 & 2.92 & 0.0002 & $* * *$ \\
\hline & $\mathrm{Ye} \times \mathrm{Si}(\mathrm{Lo})$ & 4 & 0.58 & 0.95 & 0.4312 & n.s. \\
\hline & Residual & 132 & 1.06 & & & \\
\hline \multicolumn{7}{|l|}{ Symphodus doderleini: } \\
\hline \multirow[t]{6}{*}{ All fish } & $\mathrm{Ye}$ & 2 & 2.08 & 3.74 & 0.0252 & $*$ \\
\hline & Lo & 1 & 1.49 & 5.38 & 0.0238 & $*$ \\
\hline & $\mathrm{Si}(\mathrm{Lo})$ & 2 & 1.09 & 1.96 & 0.1536 & n.s. \\
\hline & $\mathrm{Ye} \times \mathrm{Lo}$ & 2 & 2.72 & 4.90 & 0.0104 & $*$ \\
\hline & $\mathrm{Ye} \times \mathrm{Si}(\mathrm{Lo})$ & 4 & 1.28 & 1.15 & 0.3348 & n.s. \\
\hline & Residual & 132 & 36.67 & & & \\
\hline \multirow[t]{6}{*}{ Large fish } & $\mathrm{Ye}$ & 2 & 1.91 & 5.18 & 0.0068 & $* *$ \\
\hline & Lo & 1 & 0.74 & 4.03 & 0.0478 & $*$ \\
\hline & $\mathrm{Si}(\mathrm{Lo})$ & 2 & 1.20 & 3.25 & 0.0402 & $*$ \\
\hline & $\mathrm{Ye} \times \mathrm{Lo}$ & 2 & 1.99 & 5.40 & 0.0058 & $* *$ \\
\hline & $\mathrm{Ye} \times \mathrm{Si}(\mathrm{Lo})$ & 4 & 1.17 & 1.59 & 0.1810 & n.s. \\
\hline & Residual & 132 & 24.36 & & & \\
\hline
\end{tabular}

Permutational univariate ANOVAs were based on Euclidean distances. P-values were obtained using 4999 permutations of residuals under a reduced model. P-values: $* * *<0.001 ; * *<0.01 ; *<0.05$. 


\section{Figure legends}

Fig. 1. The Côte Bleue Marine Park (northwestern Mediterranean) and the Couronne MPA considered in the study. The five surveyed sites were WR1, WR2 and WR3 (Within the Reserve boundaries) and OR1 and OR2 (Outside the Reserve).

Fig. 2. Discriminant analyses plots for each year based on the binomial deviance dissimilarity measure. Analyses compared the fish assemblages in the two locations: within the MPA boundaries (black diamonds) and outside the MPA (white rectangles). There are $n=24$ observations in each location for each year.

Fig. 3. Boxplots of (a) species richness, (b) species richness of large fish, (c) diversity index of Shannon, (d) diversity index of Shannon of large fish, (e) overall fish abundance, and (f) overall abundance of large fish for each combination for the levels of factors Year and Location. There were $n=24$ transects per combination. For better readability, outlying values were not reported on (e) and (f): for total fish abundance, R.1995: 534, HR.1998: 553; R.2001: 852 and 3095 fishes; for total abundance of large fish: HR.1995: 105, and 217; R.1995: 113, 208, 215 and 511 fishes; HR.1998: 243; R.1998: 158; HR.2001: 106 and 313 fishes.

Fig. 4. Boxplots of the abundances of (a) Coris julis, (b) large individuals of Coris julis, (c) Serranus cabrilla, and (d) Symphodus doderleini for each combination of the levels of factors Year and Location. There were $n=24$ transects per combination.

Fig. 5. Multivariate regression tree constructed from the species abundance of large fish. For each split and each leaf, the number of transects were reported. On the right side of the tree, indicator species for splits (in roman numbers) and leaves (in capitals) were reported. 
Figure 1
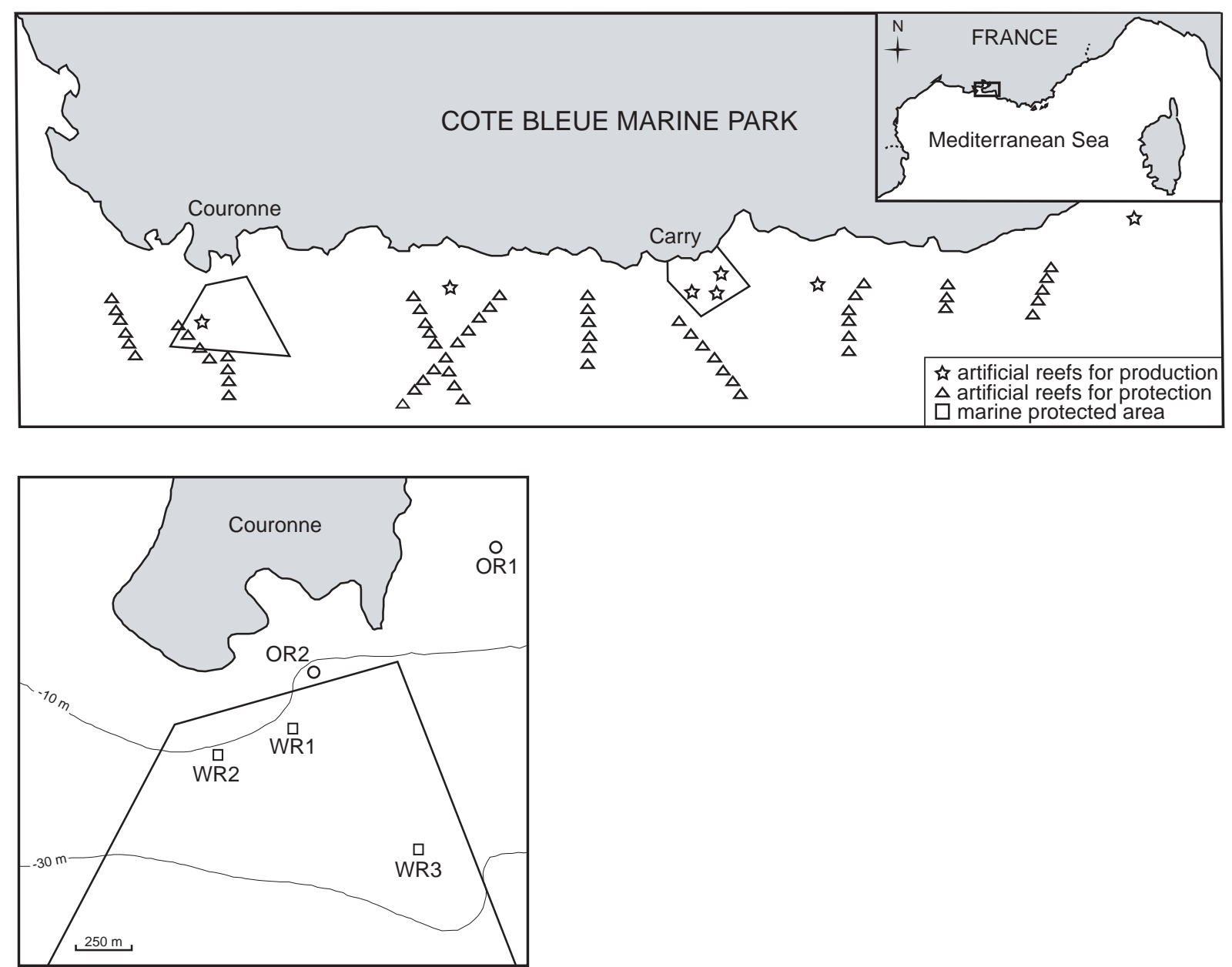
Figure 2
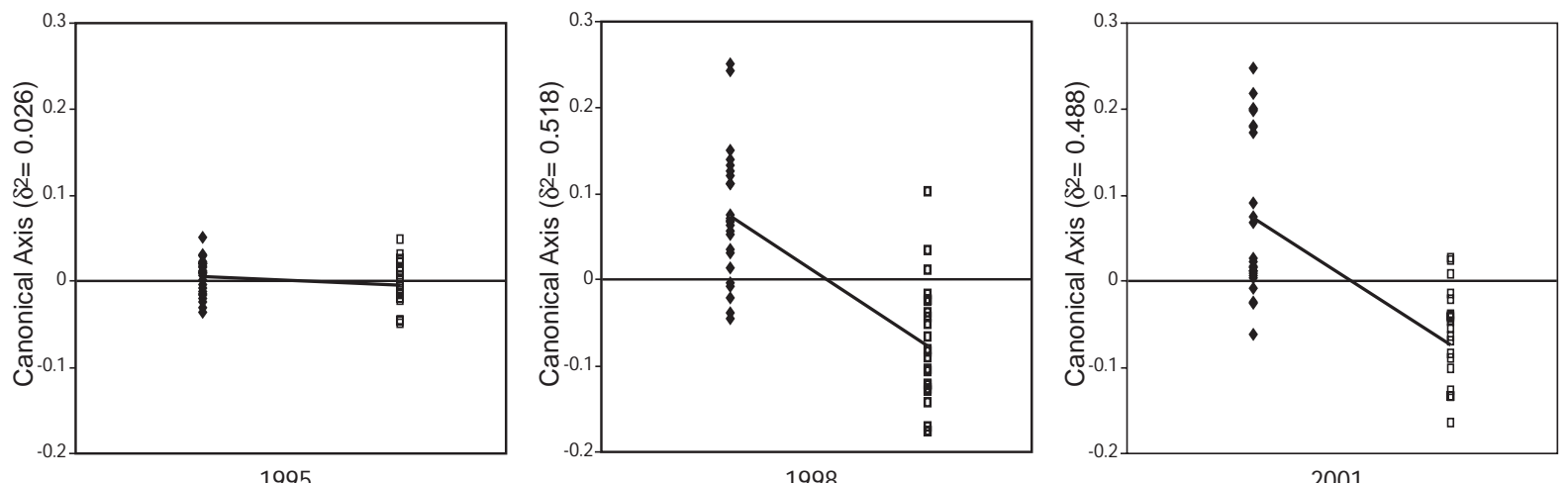

- Within MPA 口 Outside MPA 
Figure 3

(a) Species richness

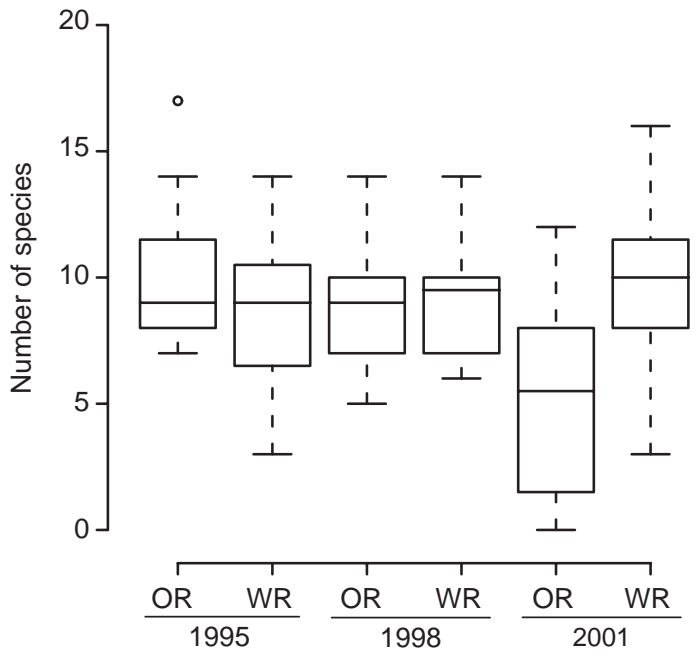

(c) Diversity of species

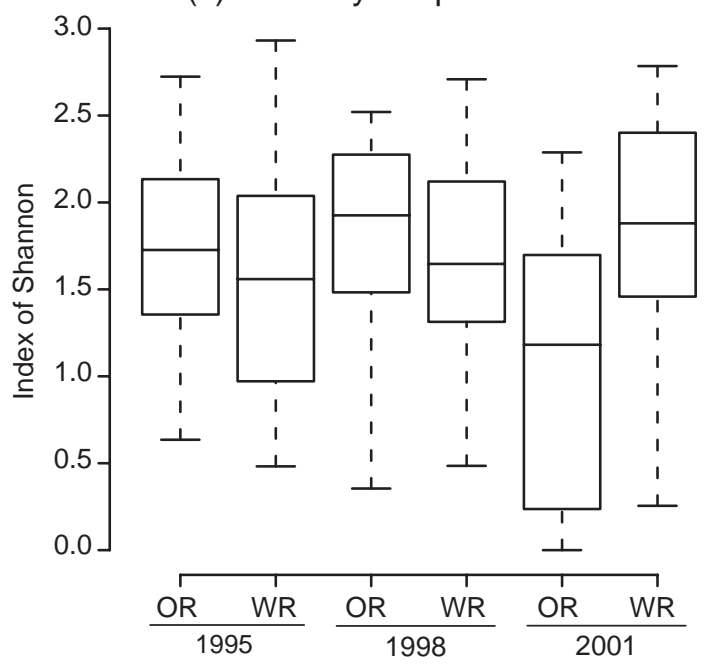

(e) Total fish abundance

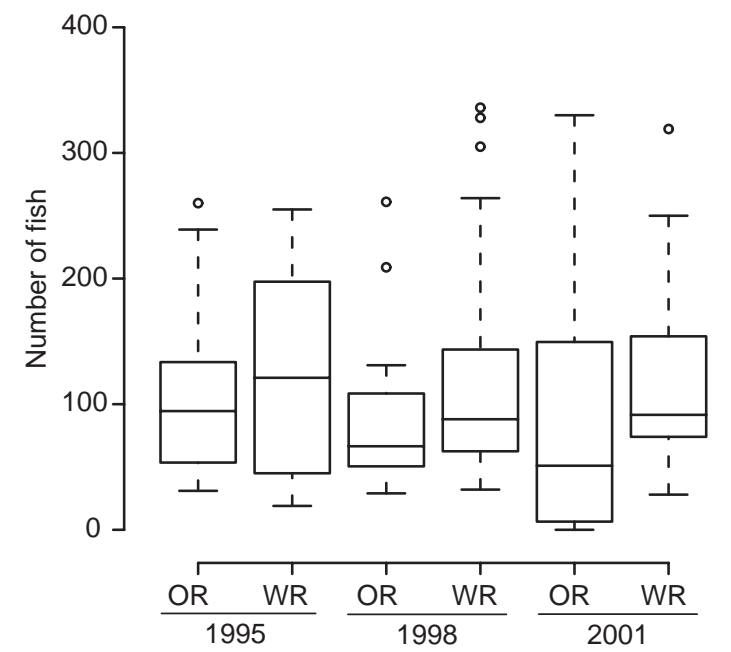

(b) Species richness of large fish

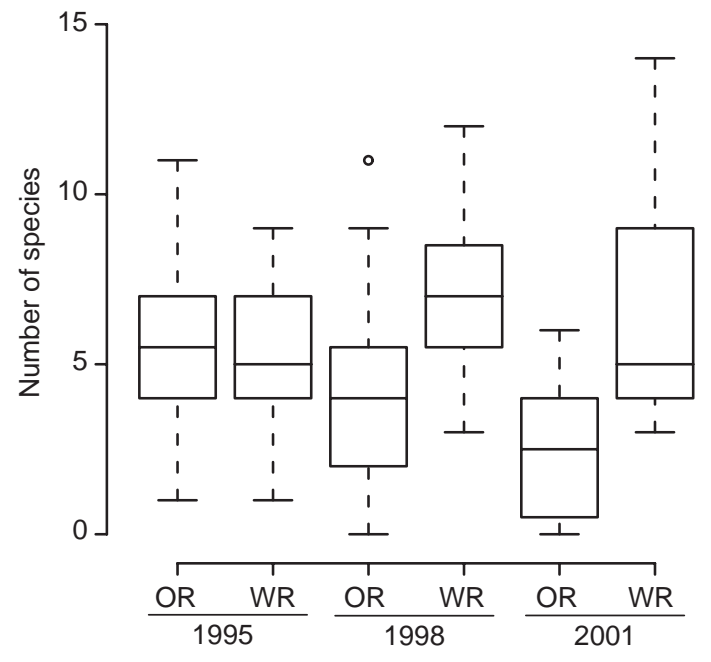

(d) Diversity of species of large fish

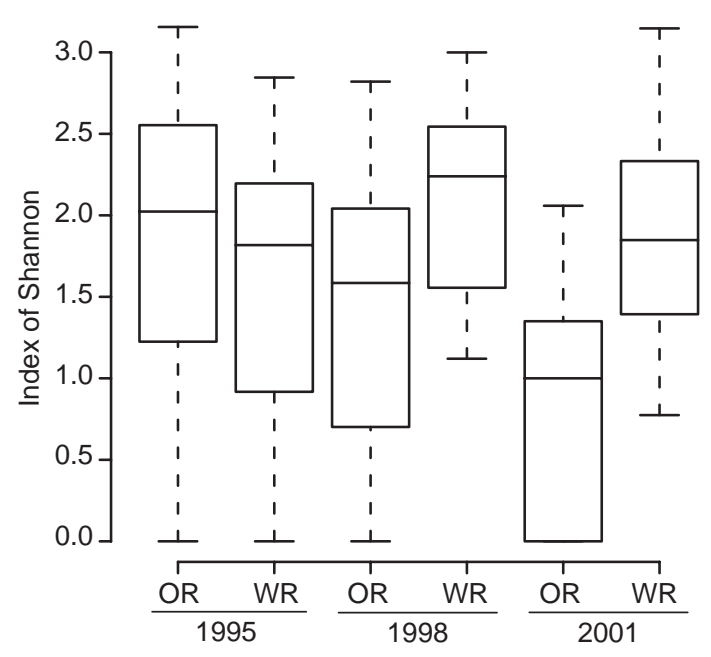

(f) Total abundance of large fish

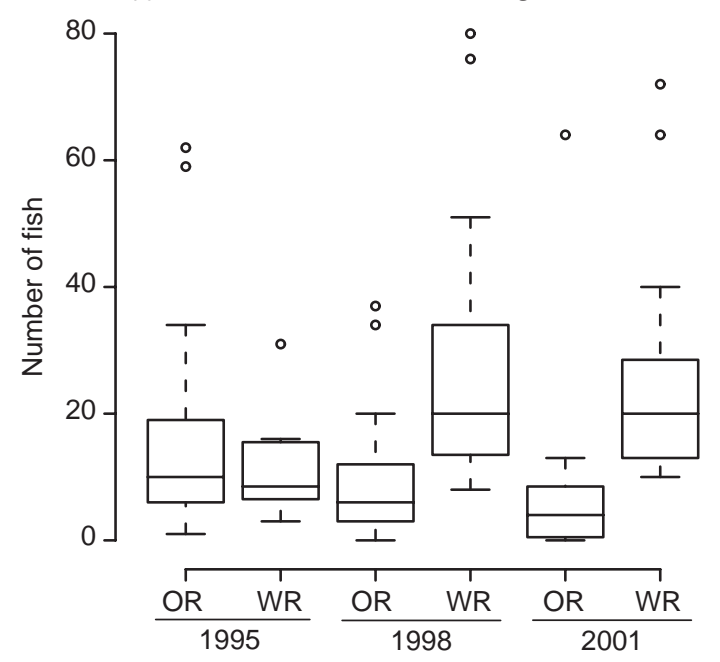


Figure 4

(a) Coris julis

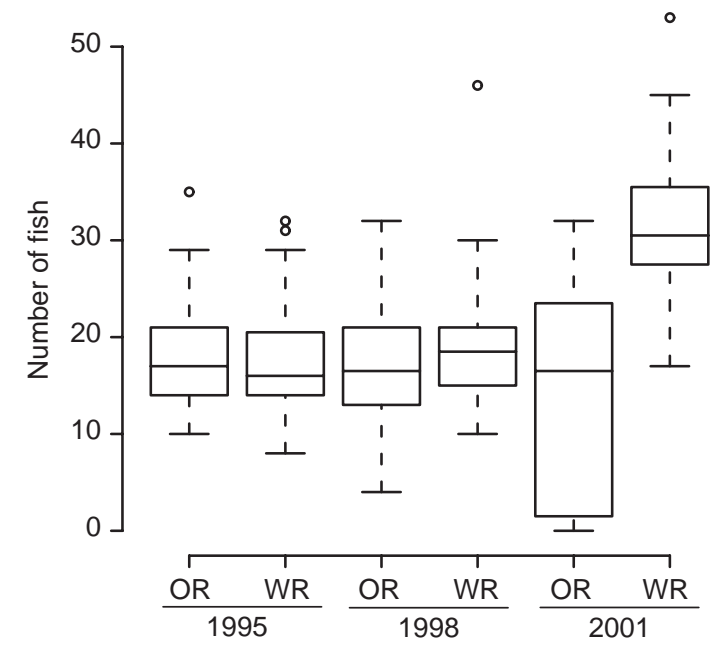

(c) Serranus cabrilla

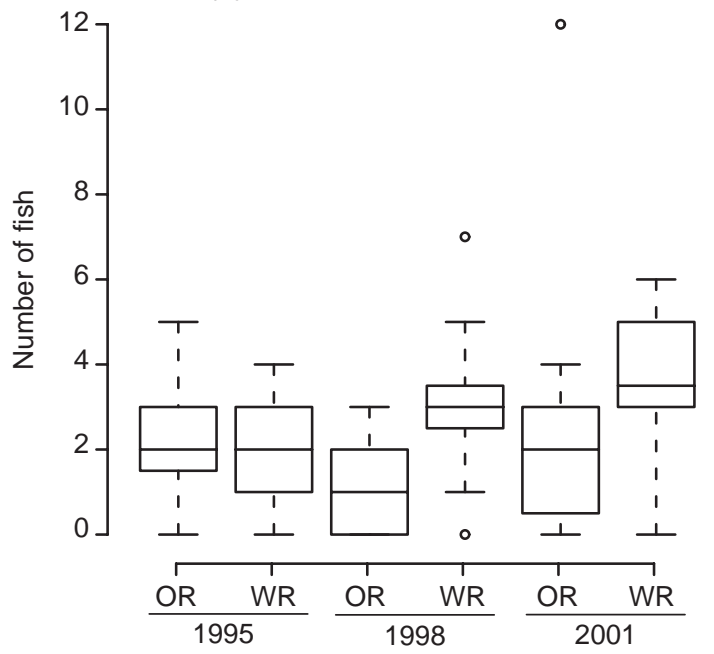

(b) Coris julis (large fish)

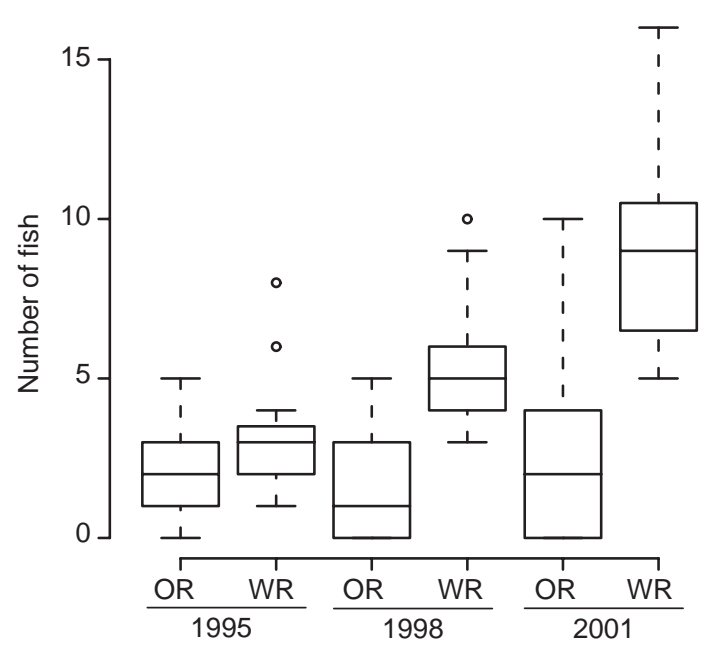

(d) Symphodus doderleini

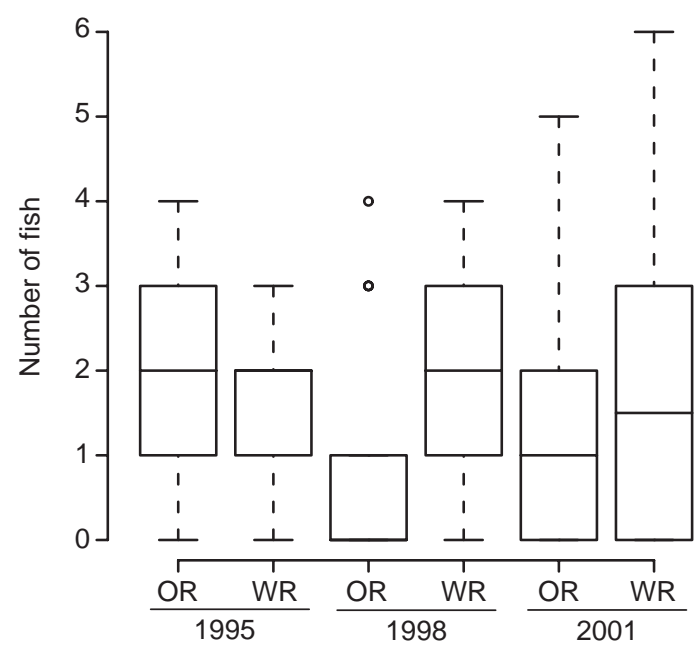




\section{Figure 5}

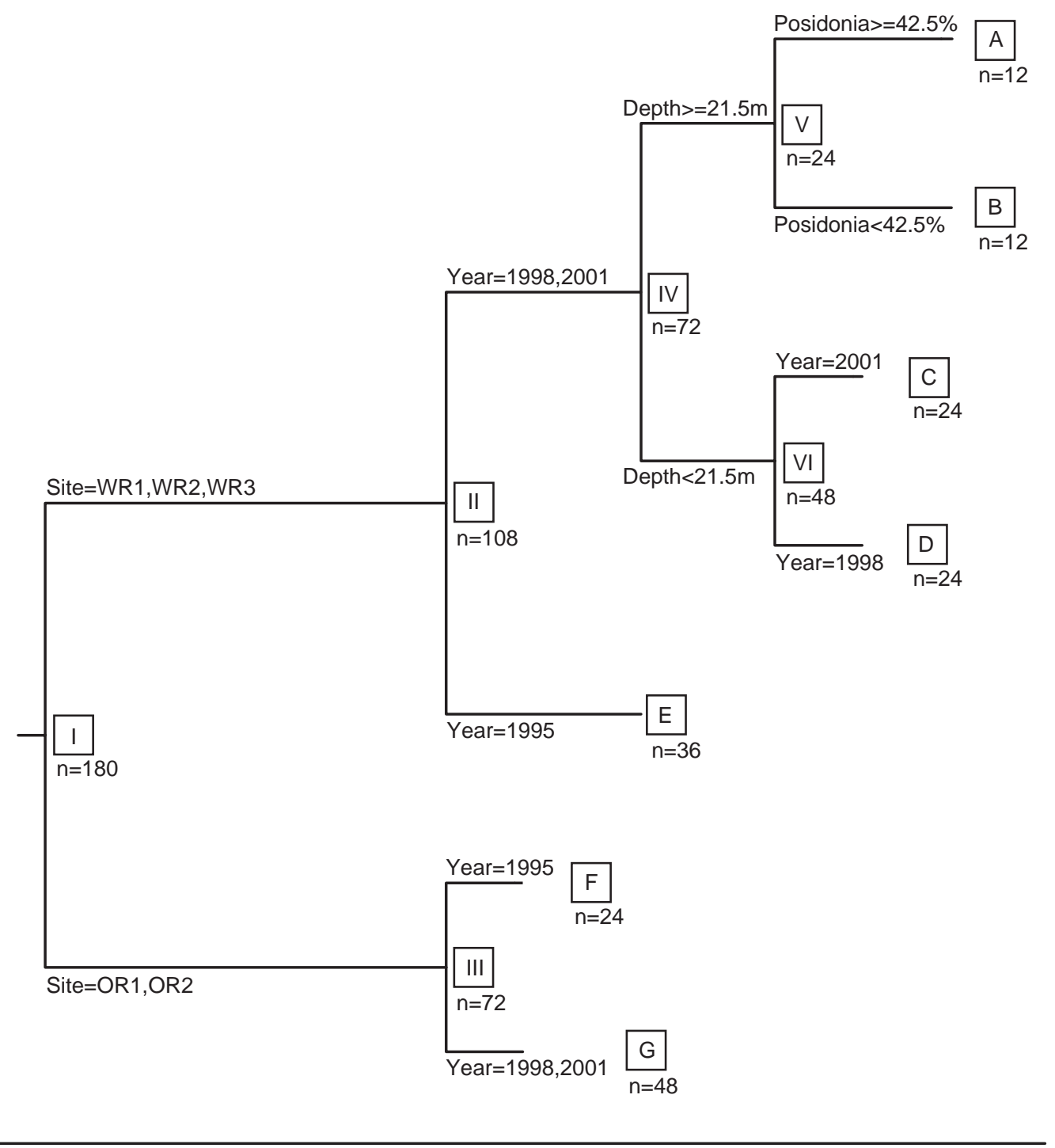

Indicator species

Coris julis

II Ctenolabrus rupestris

Serranus cabrilla

III Apogon imberbis

IV Sarpa salpa

Symphodus tinca

V Mullus surmuletus

Scorpaena porcus
Labrus merula

Labrus viridis

A Scorpaena notata

Scorpaena scrofa

Spicara maena

Anthias anthias

B Diplodus sargus

Diplodus vulgaris

F Symphodus doderleini Symphodus roissali 